\title{
Polymer backbone dynamics influence water/ion transport selectivity in membranes for water purification
}

\author{
Tianyi Xue \\ B.S., Tsinghua University, 2014 \\ A Thesis presented to the Graduate Faculty \\ of the University of Virginia in Candidacy for the Degree of \\ Master of Science \\ Department of Chemical Engineering \\ University of Virginia \\ May, 2016
}




\begin{abstract}
Water scarcity is a severe challenge facing both developing and industrialized countries. Over the past 20 years, the desalination market has been grown significantly, and polymer membrane-based water purification techniques dominate the market. More efficient and low-cost membrane-based water purification can be achieved by improving water/salt selectivity, membrane fouling resistance, etc., but these improvements rely on deep understanding of the relationships between polymer structure and water/ion transport properties.
\end{abstract}

This work discusses the effect of polymer backbone dynamics on water and salt permeability, sorption and diffusion properties. Two homogeneous, uncharged copolymers, poly(HEA-co-EA) and poly(HEMA-co-MMA) were chosen based on prerequisite material characteristics to control the influence of water uptake and polymer chemistry. Backbone dynamics were varied by using an acrylic poly(HEA-co-EA) backbone and a methacrylic poly(HEMA-co-MMA) backbone. Low water uptake $(<0.2$ $\mathrm{g}($ water $) / \mathrm{g}($ dry polymer $))$ materials, similar in water content to those used in commercial desalination membranes, were considered because the effect of backbone dynamics on transport properties was expected to be significant in low water content polymers as opposed to high water content hydrogels or ion exchange membranes.

Experimental data indicate that increasing polymer backbone rigidity results in an increase in the water/salt permselectivity and diffusion selectivity of these uncharged 
polymers. Ion sorption (thermodynamic) properties of the polymers appear to be unaffected by the change in backbone dynamics. Additionally, the polymer with the more rigid backbone (poly(HEMA-co-MMA)) exhibits greater size selectivity (quantified by ion permeability and diffusion selectivity) compared to the less rigid backbone material (poly(HEA-co-EA)). 


\section{List of Figures}

Figure 1 Global surface water scarcity. Physical scarcity indicates water resources has reached sustainable limit. Economic scarcity indicates that human/financial limit water

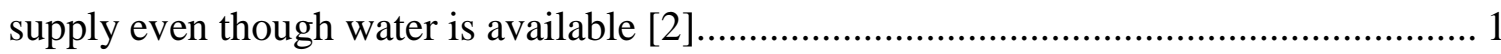
Figure 2 Total installed capacity and water price development in the desalination market [7]

Figure 3 Steady-state salt flux and salt concentration profile in a dense, non-porous

polymer [47]. 8

Figure 4 Receiver chamber solution conductivity versus permeation time in a salt permeability measurement. Permeability is calculated using the linear portion at steady state.

Figure 5 Poly(HEA-co-EA) mass versus time in water sorption process...

Figure 6 Sodium chloride sorption coefficient for poly(HEA-co-EA) (a) and poly(HEMA-co-MMA) ( $\square$ ) as a function of water uptake in $0.5 \mathrm{~mol} / \mathrm{L} \mathrm{NaCl}$ solution ... 21 Figure 7 DSC thermograms for hydrated poly(HEMA-co-MMA) and poly(HEA-co-EA) at different compositions. The thermograms were displaced vertically for clarity. 24 Figure 8 Salt permeability for poly(HEA-co-EA) (घ) and poly(HEMA-co-MMA) ( $\square$ ) as a function of water uptake in $0.5 \mathrm{~mol} / \mathrm{L} \mathrm{NaCl}$ solution 25 Figure $9 \mathrm{NaCl}$ diffusivity as a function of water uptake in $0.5 \mathrm{~mol} / \mathrm{L} \mathrm{NaCl}$ solution (a) and water diffusivity as a function of water uptake in pure water (b) for poly(HEA-co-EA) (匹) and poly(HEMA-co-MMA) ( $\square)$

Figure 10 Sorption selectivity versus water sorption coefficient for poly(HEA co EA) (匹), poly $($ HEMA-co-MMA) $(\boldsymbol{\nabla})$ and a variety of polymers reported in the literature $(\Delta)[3]$.

Figure 11 Sorption selectivity for poly(HEA-co-EA) (ם) and poly(HEMA-co-MMA) ( $\square$ ) versus water sorption coefficient in $0.5 \mathrm{~mol} / \mathrm{L} \mathrm{NaCl}$ solution 28 
Figure 12 Diffusion selectivity for poly(HEA-co-EA) (匹) and poly(HEMA-co-MMA) (口)

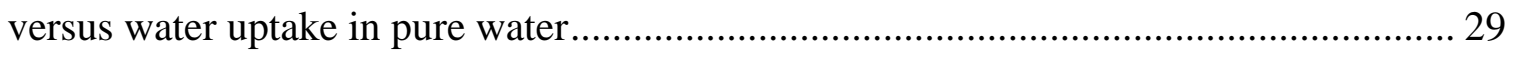

Figure 13 Schematic of simplified water activity profile in sorption process ................. 30

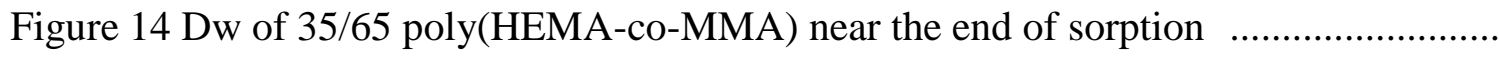
Figure 15 Diffusion coefficients for a variety of gases as a function of molar volume ... 33 Figure $16 \mathrm{NaCl} / \mathrm{KCl}, \mathrm{LiCl} / \mathrm{KCl}$ and $\mathrm{KCl} / \mathrm{KCl}$ permeability selectivity for poly(HEA-co-EA) (匹) and poly(HEMA-co-MMA) ( $\square$ ) versus average diffusion

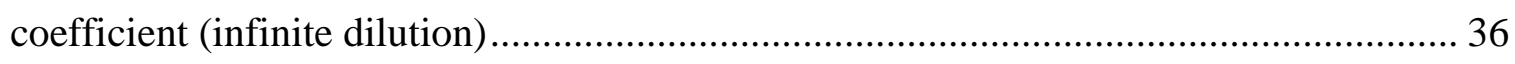
Figure $17 \mathrm{NaCl} / \mathrm{KCl}, \mathrm{LiCl} / \mathrm{KCl}$ and $\mathrm{KCl} / \mathrm{KCl}$ diffusion selectivity for poly(HEA-co-EA) (匹) and poly(HEMA-co-MMA) ( $\square$ ) versus average diffusion coefficient. ..... 38 


\section{List of Tables}

Table 1 chemical structures of the monomers and cross-linker, water uptake (defined as equation 8) and glass transition temperatures of homopolymers................................. 10

Table 2 Copolymer compositions, density, $\mathrm{Wu}$ and $\mathrm{Kw}$ in $0.5 \mathrm{~mol} / \mathrm{L} \mathrm{NaCl}$ and in pure water.

Table $3 \mathrm{Tg}$ of dry estimated by Flory-Fox equation................................................ 23

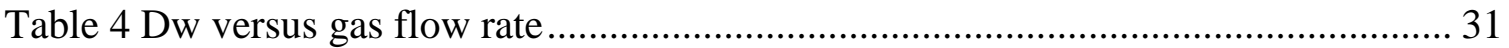

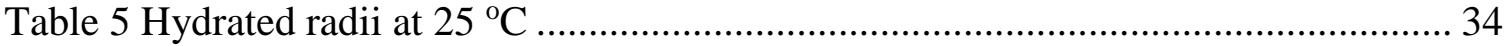

Table 6 Average diffusion coefficients of $\mathrm{KCl}, \mathrm{NaCl}$ and $\mathrm{LiCl}$ at infinite dilution ......... 34

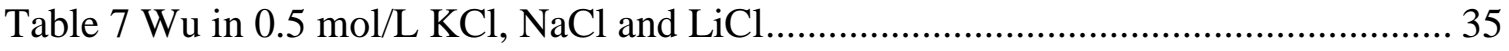

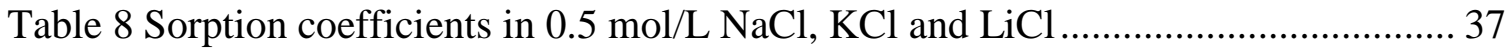




\section{Acknowledgements}

I would like to thank my advisor Geoff Geise for his advice and inspiration on my project.

I also want to thank our group members, Yuanyuan Ji, Huan Zhang, Shivanni Sukha and Drew Biedermann, and Prof. Carta's group, Mimi Zhu, Shaojie Zhang, Jing Guo, Arch Creasy, Jason Reck and Andreas Alberti, for their help. I would like to thank Ricky Buchanan for helping me with equipment. I also thank Prof. Eric Anderson for teaching me how to use the DSC insrument. I also want to thank my parents and all my friends for their kind support, especially Xiangyi Kong, Yiran Wang, Spring Dong, Colin Qi, Jiahan Xie and Kehua Yin. This research was supported by start-up support at the University of Virginia. 


\section{Table of Contents}

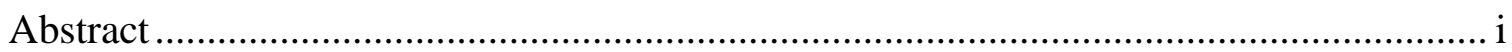

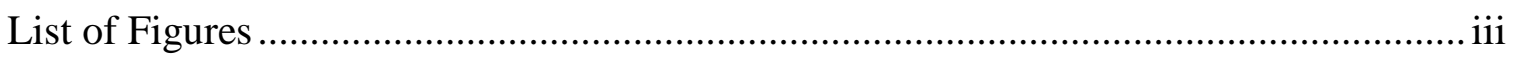

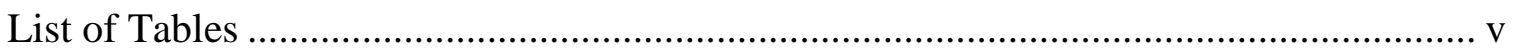

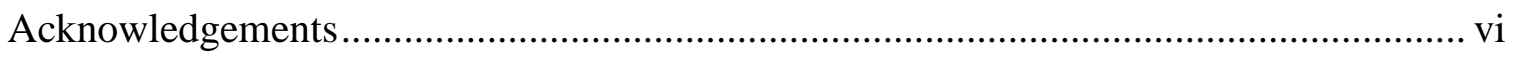

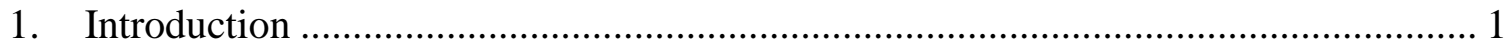

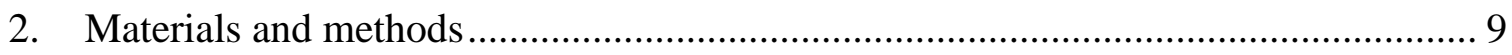

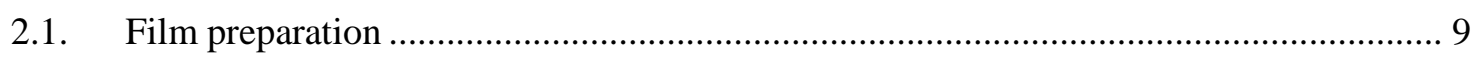

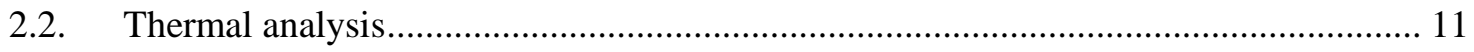

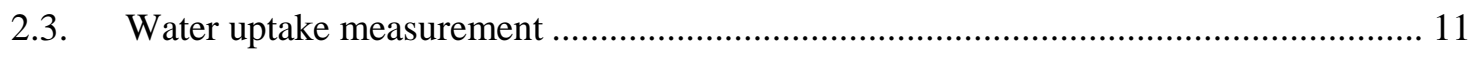

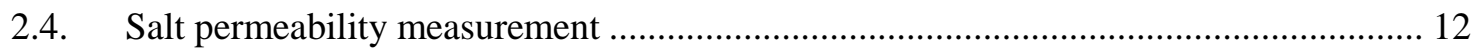

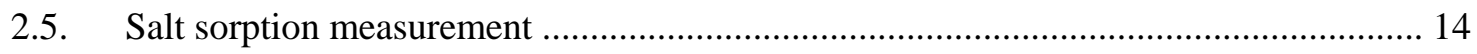

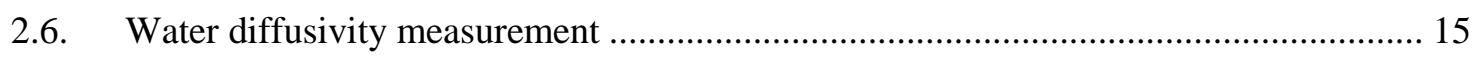

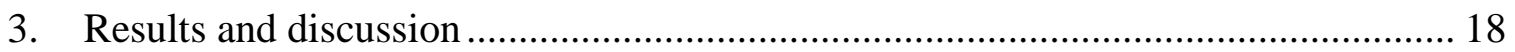

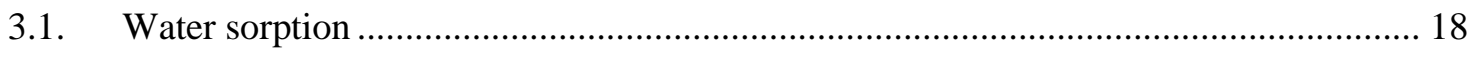

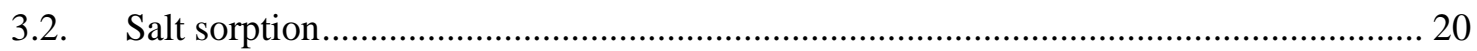

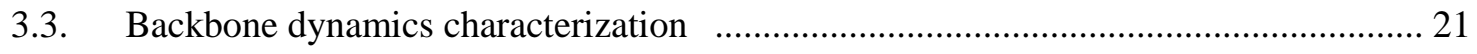

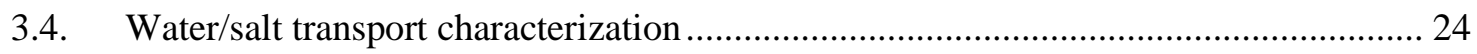

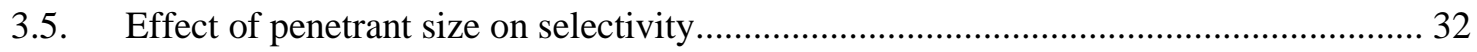

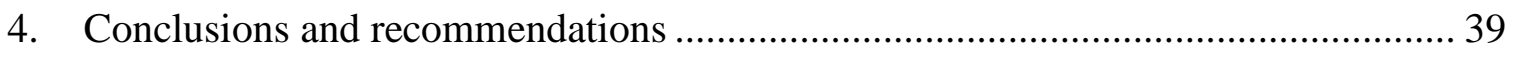

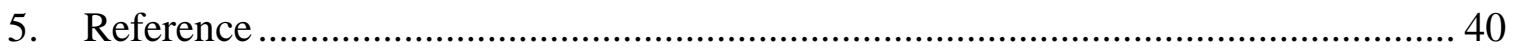




\section{Introduction}

Demand for freshwater and energy are increasing significantly as a result of growing populations and economies in both developing and industrialized nations. Currently, more than 1 billion people lack access to safe drinking water [1]. The water supply is limited in many countries because of scarce water resources or underdeveloped water infrastructure (Fig. 1).

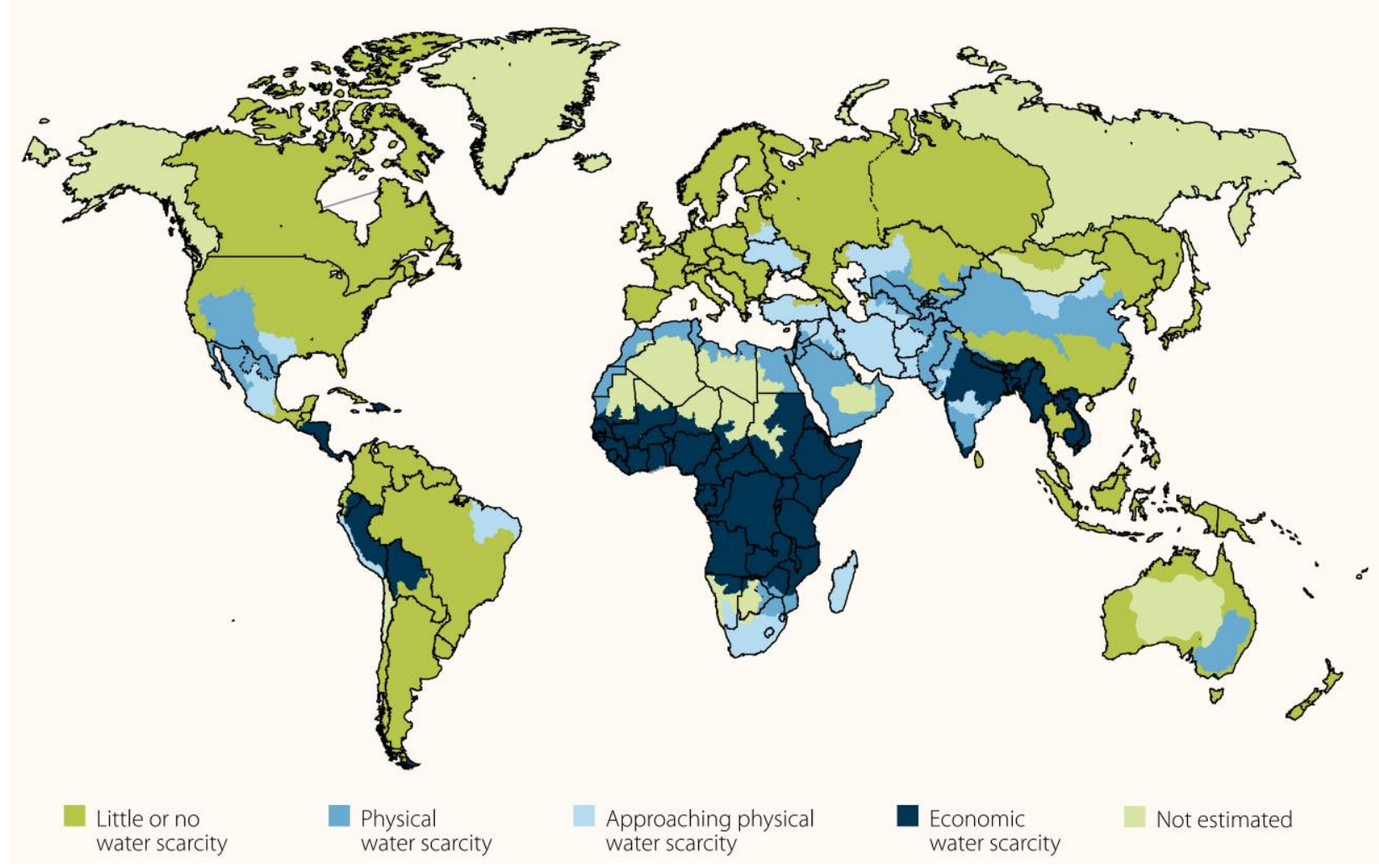

Figure 1 Global surface water scarcity. Physical scarcity indicates water resources have reached a sustainable limit. Economic scarcity indicates that human/financial constraints limit water supply, but water is available [2].

In addition to increased demand for water, electricity demand is projected to grow by roughly $70 \%$ by 2035 [2]. Water and energy are highly interlinked [2][3][4]. Energy is 
required for water purification (pumping and treatment) and water resources are needed in energy production. 7-15 $\mathrm{L}$ water is consumed to make $1 \mathrm{~L}$ of petroleum based fuel [5]. For natural gas, 20-50 L of water is needed to produce a barrel equivalent of oil [6]. These examples underscore the need for more efficient, sustainable and low-cost water and energy resources.

Since the 1960s, growth in desalination has significantly increased to alleviate water stress by increasing access to purified water resources (Fig. 2) [7][8][9]. Global water desalination capacity reached 86 million $\mathrm{m}^{3} /$ day in 2015 . In contrast, world-wide crude oil production was 13 million $\mathrm{m}^{3} /$ day in 2015 , which emphasizes the magnitude of the amount of water that is desalinated each day [10]. Water purification, however, is not affordable for many developing countries and for high water consuming services such as agriculture, due to its high capital, energy and operating cost [1]. In Africa, materials, electricity and staff costs are relatively high so that maintenance of water treatment is often insufficient, which leads to frequent outages [2]. 


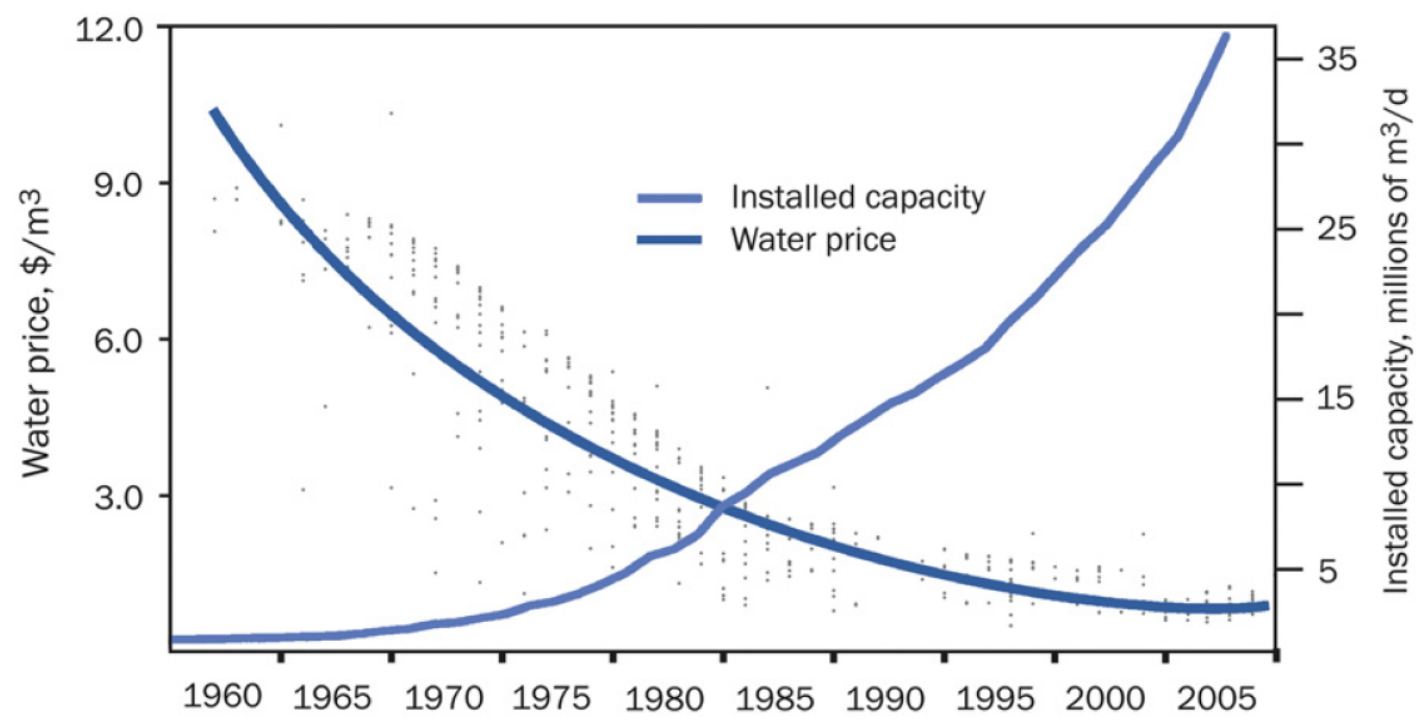

Figure 2 Total installed capacity and water price in the desalination market since 1960[7]

The majority of desalination plants worldwide use membrane based desalination technology, which had a 64\% market share in 2012 [11]. Typical energy consumption of the major membrane-based desalination technologies, seawater reverse osmosis and brackish water reverse osmosis, is $2.6 \mathrm{KWh}$ and $1.0 \mathrm{KWh}$ per cubic meter of fresh water produced, respectively [8]. The minimum theoretical energy has been derived assuming a reversible thermodynamic process [4]. For seawater (taken as $35 \mathrm{~g} / \mathrm{L} \mathrm{NaCl}$ ), the minimum energy of a desalination process at $50 \%$ recovery, which is the percent of seawater converted to purified water, is $1.06 \mathrm{kWh} / \mathrm{m}^{3}$. For brackish water (taken as $5 \mathrm{~g} / \mathrm{L}$ $\mathrm{NaCl}$ ), the minimum energy at $50 \%$ recovery is $\sim 0.2 \mathrm{kWh} / \mathrm{m}^{3}$ [12]. Because water purification is done on an extraordinary large scale, improvements in energy efficiency would have a significant impact on energy consumption. It is noteworthy to point out that, compared with seawater desalination, the energy efficiency of brackish water 
desalination can be improved to a greater extent since the practical energy cost of SWRO is roughly a factor of 2 above the minimum theoretical energy required to do the separation.

Furthermore, membranes are being challenged with increasing contaminated waters, so materials that can withstand fouling environments and/or aggressive cleaning protocols are needed. In many cases, such materials do not have the necessary water and salt transport properties to be commercially viable. Thus, structure-property relationships are needed to guide material development to address these challenges [3]:

One way to increase the energy efficiency of practical water purification processes is to increase the intrinsic water/salt selectivity of membrane polymers [13]. It is challenging to increase selectivity without reducing water permeability as illustrated by the permeability and selectivity tradeoff [14], which can be related to fundamental free volume transport principles. In addition, membrane fouling is a major concern in water treatment applications, and it results in water flux reduction in many membrane separation processes [1] [4] [15] [16]. Fouling is sensitive to membrane chemistry, morphology and structure [1] [17]. Membranes are often coated with hydrophilic thin film coatings to mitigate fouling and extend the overall membrane life [1]. Despite efforts over several decades, the challenge of developing fouling resistant membranes still exists, and while some strategies for modifying thin film composite membranes work reasonably well, the challenge of membrane fouling will continue to persist, perhaps particularly for new membrane chemistries [8]. In both developing and industrialized countries, 
increasing pollutants in water such as heavy metals, organic wastes and waterborne pathogens brought by human activity require new strategies for designing membranes that remove multiple contaminants and resist stresses and degradation [1].

These challenges in water purification membrane performance can be addressed by materials chemistry and engineering, but in order to do so in a rational manner, it is critical to develop relationships between polymer structure and water/ion transport properties [3]. In addition to aiding in the design of membranes for water purification technologies such as reverse osmosis (RO) and forward osmosis (FO) [18][19], such structure-property relationships may also contribute to designing membranes for power generation processes [20][21], including flow batteries [22], pressure-retarded osmosis (PRO) [23], reverse electrodialysis (RED) [24] and microbial fuel-cells (MFCs), which all rely on membranes to at least some extent to control rates of water and/or ion transport. In addition to intrinsic selectivity properties, all of these technologies require materials that interact well with their environment (i.e., materials that do not degrade or foul during use).

The solution-diffusion model is widely used to describe water/ion transport in desalination membranes [25]. Desalination membrane materials, such as those materials used in RO membranes, are often considered to be non-porous in the sense that void space within the polymer matrix exists between polymer chains, this void space is often on the order of several angstroms, and it is more dynamic compared to rigid pore structures found in ultrafiltration or microfiltration membranes [3][26][27][28]. 
According to the model, penetrants first dissolve in the polymer matrix, then diffuse through the polymer down a concentration gradient, and finally desorb from the polymer. In systems where the penetrant concentration is relatively low (e.g., gas separation membranes and some desalination membranes), transport is believed to occur via diffusional jumps between free volume elements that are gated by segmental motions of polymer chains; a penetrant within a free volume cavity in the polymer matrix can jump to another cavity when collective segmental motion of the polymer chains results in a configuration that provides space for the penetrant to execute the jump [29][30]. The rate-determining step of the diffusion process is believed to be the opening and closing of these transient gaps between polymer chains [31]. Therefore, the transport process is expected to be sensitive to polymer chain dynamics and free volume.

In gas separation membranes, permeability and diffusivity correlate with segmental mobility [31]. Penetrants with greater kinetic diameter show lower diffusivity in a given polymer. Additionally, polymers with a rigid backbone tend to be more size selective to penetrants compared to polymers with a flexible backbone [32][33]. A potential strategy to increase diffusivity selectivity without reducing permeability is to increase the polymer chain stiffness and inter-chain spacing (free volume) simultaneously [34].

Polymer chain mobility has been related with water flux and salt rejection of water swollen polymers [35][36][37]. However, water flux and salt rejection both depend on experimental operating conditions (unlike intrinsic permeability and selectivity 
properties) [13]. Importantly, the water uptake of the polymer membranes, which can strongly influence transport properties, was not controlled in these studies [3][38].

This work discusses the effect of polymer backbone dynamics on the fundamental water and ion transport properties of hydrated polymers. Successfully evaluating this relationship requires well-controlled polymers. In this study, four required material characteristics were identified. The polymers in this study were designed to have 1) different backbone rigidities (segmental dynamics), 2) similar chemical structure, 3) comparable and low water uptake values to control the influence of overall free volume, 4) as homogeneous a structure as possible. The reason of preparing low water content polymers is that the polymers used in commercial materials often sorb little water (e.g. less than $10 \%$ by mass). Furthermore, water and ion transport strongly depends on polymer water uptake, so it is imperative to control water uptake and compare materials at comparable water content. Two uncharged copolymers, poly(HEA-co-EA) and poly(HEMA-co-MMA) were prepared to meet the strict requirements of this study (see section 2.1 for definitions of the acronyms). The HEMA homopolymer has a more rigid backbone than HEA because the methyl groups on the backbone of poly(methacrylates) increase the energy barrier for segmental motion compared to poly(acrylates) that do not have the additional methyl group (as characterized by DSC Tg measurements). Co-monomers, EA and MMA, were added to adjust water uptake of polymers, and polymer compositions were chosen to avoid phase separation. The backbone dynamics, 
water/ion permeability, solubility and diffusivity were characterized to determine the influence of backbone rigidity on water/salt transport selectivity.

Salt diffuses through a thin polymer membrane down a concentration gradient as illustrated in Fig. 3. The salt flux, $n_{s}$, through a solution-diffusion membrane (at steady state) can be derived by integrating Fick's law for 1-D transport:

$$
n_{s}=D_{s} \frac{C_{s 0}^{m}-C_{s L}^{m}}{L}
$$

where $C_{s 0}^{m}$ and $C_{s L}^{m}$ are salt concentration in the membrane at the feed and permeate faces of the film, respectively. $D_{S}$ is salt diffusion coefficient. $L$ is the film thickness [3]. Salt permeability, $P_{S}$, is defined as

$$
P_{S} \equiv \frac{n_{s} L}{C_{s 0}^{S}-C_{s L}^{S}}
$$

Water or salt sorption coefficient, $K_{i}$ is defined as

$$
K_{i} \equiv \frac{C_{i}^{m}}{C_{i}^{s}}
$$

where $C_{i}^{m}$ is the concentration of penetrant $\mathrm{i}$ in the membrane and $C_{i}^{S}$ is the concentration in solution. The sorption coefficient converts the membrane phase concentrations (in Eqn. 1) to solution phase concentrations (in Eqn. 2). Therefore, at

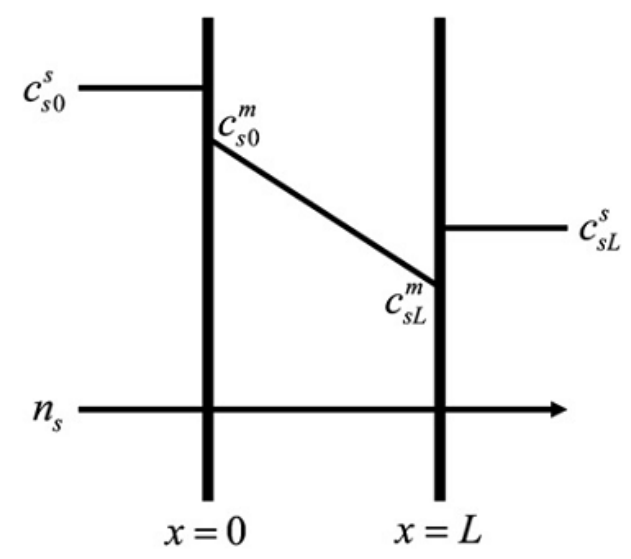


steady state, the salt permeability in solution diffusion membranes can be described by

$$
P_{S}=K_{S} D_{S}
$$

where $D_{i}$ is the concentration averaged diffusion coefficient of penetrant $i$. The water/salt diffusion selectivity, $\alpha_{D}$ and sorption selectivity, $\alpha_{K}$ values are defined as:

$$
\begin{gathered}
\alpha_{D}=\frac{D_{W}}{D_{S}} \\
\alpha_{K}=\frac{K_{W}}{K_{S}}
\end{gathered}
$$

Salt rejection, $R$, is often used as a measure of salt selectivity [3]. $R$ is defined by the salt concentrations of feed and permeate solutions in a filtration process. Salt rejection is related to selectivity as

$$
\mathcal{R}=\frac{C_{\text {feed }}-C_{\text {permeate }}}{C_{\text {feed }}}=\frac{\alpha \frac{\overline{V_{w}}}{R T}(\Delta p-\Delta \pi)}{1+\alpha \frac{\overline{V_{w}}}{R T}(\Delta p-\Delta \pi)}
$$

where $\alpha$ is permeability selectivity, $R$ is gas constant, $\Delta p$ is the pressure difference, $\Delta \pi$ is the osmotic pressure across the polymer film. Equation 7 shows that salt rejection is dependent on operating conditions since increasing $(\Delta p-\Delta \pi)$ results in an increase in $\mathcal{R}$. Equation 7 does not strictly apply in the limit $(\Delta p-\Delta \pi) \rightarrow \infty$, but it is often applicable for practical desalination applications [39].

\section{Materials and methods}

\subsection{Film preparation}

Crosslinked poly(HEA-co-EA) and poly(HEMA-co-MMA) films were prepared by UV-initiated free radical polymerization. The monomers were 2-hydroxyethyl acrylate 
(HEA), 2-hydroxyethyl methacrylate (HEMA), ethyl acrylate (EA) and methyl methacrylate (MMA) (Sigma-Aldrich). The photo-initator was 1-hydroxycyclohexyl phenyl ketone (HCPK) (Sigma-Aldrich), and poly(ethylene glycol) diacrylate (PEGDA, average $\mathrm{Mn}=250 \mathrm{~g} / \mathrm{mol}$, Sigma-Aldrich) was the crosslinker. Structures of the monomers and the crosslinker are shown in Table 1. For all materials, $3 \mathrm{wt} \%$ PEGDA

Table 1 Chemical structures of the monomers and cross-linker, water uptake (defined using equation 8) and glass transition temperatures of homopolymers.|

\begin{tabular}{|c|c|c|c|}
\hline Monomer & Monomer structure & $\begin{array}{l}\text { Homopolymer } W_{u} \text { (with } 3 \% \text { PEGDA } \\
\text { crosslinker) }\left[\mathrm{g}\left(\mathrm{H}_{2} \mathrm{O}\right) / \mathrm{g}(\text { dry polymer })\right]\end{array}$ & $\mathrm{Tg} /{ }^{\circ} \mathrm{C}$ \\
\hline HEA & & 1.60 & 15 \\
\hline HEMA & & 0.60 & 60 \\
\hline EA & & 0.01 & -24 \\
\hline MMA & & 0.01 & 120 \\
\hline PEGDA & & 1 & I \\
\hline
\end{tabular}

and $0.1 \mathrm{wt} \%$ HCPK (based on the mass of monomer mixtures) were used. After preparing the pre-polymerization mixture, the solution was confined between quartz plates. Spacers were placed between the quartz plates to control the thickness of the film. To cure the pre-polymerization mixture, the solution was irradiated with $120 \mu \mathrm{J} / \mathrm{cm}^{2} 254 \mathrm{~nm}$ UV light for $120 \mathrm{sec}$ for poly(HEA-co-EA) and $500 \mathrm{sec}$ for poly(HEMA-co-MMA) at room temperature. Polymer films were prepared with thickness that ranged from 50-200 $\mu \mathrm{m}$. 
The crosslinked polymers were soaked in DI water following the curing step to remove any unreacted monomer from the film. Films prepared for salt transport property measurements were, in some cases, stored in sodium chloride solutions until use.

\subsection{Thermal analysis}

The thermal transitions of poly(HEA-co-EA) and poly(HEMA-co-MMA) were analyzed using differential scanning calorimetry (DSC) (TA Instruments Q1000). Hydrated polymer samples (5-10 mg) were sealed in hermetic aluminum sample pans to keep the samples in a hydrated state, initially heated to $150{ }^{\circ} \mathrm{C}$, then quenched to $-80{ }^{\circ} \mathrm{C}$, and scanned twice between $-80{ }^{\circ} \mathrm{C}$ and $150{ }^{\circ} \mathrm{C}$ at $10{ }^{\circ} \mathrm{C} / \mathrm{min}$ under nitrogen purge flow. The glass transition temperature ( $\mathrm{Tg}$ ) was determined as the midpoint of the heat capacity change during the second heating scan.

\subsection{Water uptake measurement}

Polymer samples were equilibrated in DI water or $0.5 \mathrm{~mol} / \mathrm{L}$ aqueous sodium chloride solution for at least $24 \mathrm{~h}$. Subsequently, the wet mass of equilibrated hydrated polymer, $m_{w e t}$, was measured quickly after wiping the surface water from the film. Then, the samples were dried in a vacuum oven at room temperature until equilibrium was reached (typically 24 hours). The samples were quickly removed from the oven and the dry polymer mass, $m_{d r y}$, was measured. Water uptake, $w_{u}$, was calculated as:

$$
w_{u}=\frac{m_{w e t}-m_{d r y}}{m_{d r y}}
$$


Assuming volume additivity, the volume fraction of water in the polymer, $\phi_{w}^{m}$, can be calculated as:

$$
\phi_{w}^{m}=\frac{w_{u}}{w_{u}+\rho_{w} / \rho_{P}}
$$

where $\rho_{w}$ is the density of pure water, taken as $1.0 \mathrm{~g} / \mathrm{cm}^{3}$ and $\rho_{P}$ is the density of the dry polymer, which was measured based on Archimedes' principle, using a Mettler Toledo density determination kit [40]. The dry mass of the polymer sample and its mass in an auxiliary solvent were determined using the density kit. $3 \mathrm{M}^{\mathrm{TM}}$ Fluorinert $^{\mathrm{TM}}$ Electronic Liquid FC-770 was used as auxiliary solvent because it was not expected to sorb significantly into the polymer [41]. Using the density measurement and Euqation 9, the water sorption coefficient, $K_{w}$, was calculated as:

$$
K_{w}=\frac{\phi_{w}^{m} M_{w}}{C_{w}^{s} V_{w}}
$$

where $C_{w}^{S}$ is the water concentration in the bulk solution, $M_{w}$ is the molar mass of water, $18 \mathrm{~g} / \mathrm{mol}$ and $V_{w}$ is the molar volume of water, $18 \mathrm{~cm}^{3} / \mathrm{mol} . K_{w}$ is effectively the volume fraction of water in the polymer since $M_{w} / C_{w}^{s} V_{w} \approx 1$ [42].

\subsection{Salt permeability measurement}

Salt permeability was measured using a custom-built cell consisting of two jacketed chambers, donor and receiver chambers, separated by the polymer film. The donor chamber was filled with $100 \mathrm{~mL}$ of $0.5 \mathrm{~mol} / \mathrm{L} \mathrm{NaCl}$ solution while the receiver chamber was filled with $100 \mathrm{~mL}$ of DI water. Silicone rubber gaskets were used to seal the chambers, and the chambers were mechanically stirred at a rate of $200 \mathrm{rpm}$. The 
conductivity of the receiver chamber solution was recorded as a function of time using a conductivity meter (Cond 7310, WTW, Germany). The aqueous $\mathrm{NaCl}$ concentration was calculated from the conductivity data using a calibration curve. Temperature was maintained at $25{ }^{\circ} \mathrm{C}$ by circulating water through the jacket using a circulator with temperature control. Salt transport was modeled as one-dimensional Fickian diffusion, and the steady-state salt permeability, $P_{s}$, was regressed using:

$$
-\frac{V L}{2 A} \ln \left(1-2 \frac{C_{R}(t)}{C_{D}(0)}\right)=P_{S} t
$$

where $V$ is the volume of the donor and receiver chambers $(100 \mathrm{~mL}), A$ is the area available for mass transfer, $t$ is time, $C_{R}(t)$ is the salt concentration in receiver chamber at time $t$, and $C_{D}(0)$ is the initial salt concentration in donor chamber, which was 0.5 mol/L [43]. An example of receiver chamber solution conductivity as a function of permeation time is shown in Fig. 4. 


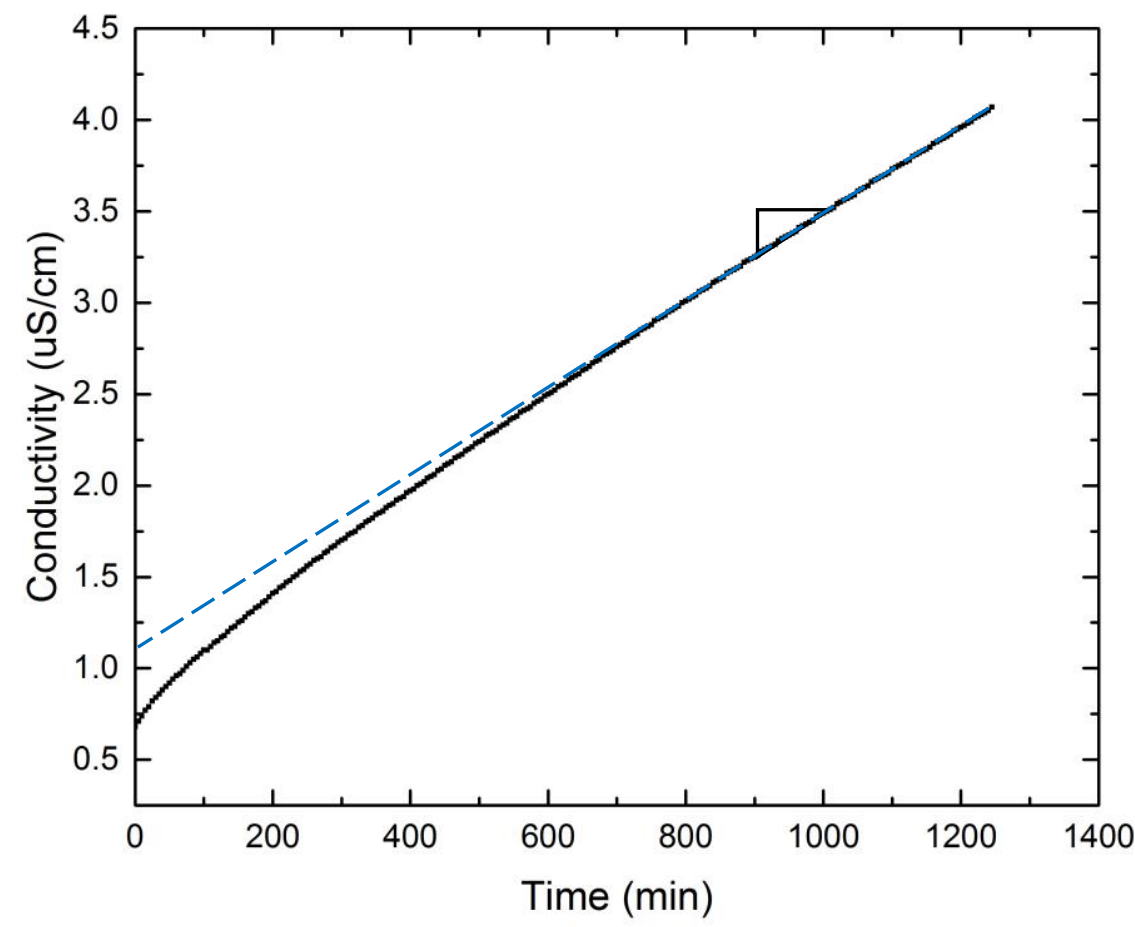

Figure 4 Receiver chamber solution conductivity versus permeation time in a salt permeability measurement. Permeability is regressed using the linear portion at steady state.

\subsection{Salt sorption measurement}

The extent of ion sorption (or partitioning) into the polymer film from solution was measured using an equilibration and desorption method [44]. Polymer films were first immersed in $0.5 \mathrm{~mol} / \mathrm{L} \mathrm{NaCl}$. The equilibrated polymers were then soaked in DI water of volume $V_{d}$ so that the chloride ions (absorbed from external solution) could fully desorb into the initially DI water. The immersion time and desorption time were estimated using the characteristic time of the diffusion process, $L^{2} / D_{\mathrm{s}}$, where $D_{\mathrm{s}}$ is the salt diffusion coefficient. This characteristic time was roughly $10 \mathrm{~h}$, so the samples were 
soaked in salt solution or pure water for at least 3 days to reach equilibrium. The desorption volume, $V_{d}$, was chosen (iteratively) to ensure that the desorption concentration was near $1 \mathrm{mg}(\mathrm{NaCl}) / \mathrm{L}$. This concentration target was chosen so that the concentration of the desorption solution was sufficiently low to facilitate complete desorption but still high enough to be accurately measured. A typical value of $V_{d}$ was 20 mL.

The ion sorption coefficient, $K_{S}$, was determined as:

$$
K_{s} \equiv \frac{C_{s}^{m}}{C_{s}^{s}}=\frac{C_{d} V_{d}}{C_{s}^{s} V_{p}}
$$

where $C_{S}^{S}$ is the $\mathrm{NaCl}$ concentration in the external solution $(0.5 \mathrm{~mol} / \mathrm{L} \mathrm{NaCl}), C_{S}^{m}$ is the concentration in the polymer film, $C_{d}$ is the concentration of desorption solution, $V_{d}$ is the desorption volume and $V_{p}$ is the volume of polymer at hydrated state in the external solution [44]. The volume of the polymer sample was determined by measuring the thickness and area of the film. Film area was measured by analyzing a photo of the hydrated polymer using ImageJ software. Typical values of the thickness and area were $150-200 \mu \mathrm{m}$ and $1-3 \mathrm{~cm}^{2}$, respectively. The uncertainty in the thickness and area measurements was less than $10 \%$, and the polymer volume uncertainty was roughly $15 \%$ based on standard error propagation calculations.

\subsection{Water diffusivity measurement}

The water diffusion coefficient was determined by kinetic gravimetric sorption studies. The measurements were performed using a dynamic vapor sorption analyzer 
(Q5000 SA, TA instruments), in which the sample and a reference pan were placed in a humidity chamber. The relative humidity was controlled by mixing dry nitrogen gas and humidified nitrogen gas at a computer-controlled ratio. The purge flow in the humidity chamber was $200 \mathrm{~mL} / \mathrm{min}$. After equilibration at $25{ }^{\circ} \mathrm{C}$, the polymer sample was maintained isothermally at $93 \% \mathrm{RH}$ until the weight change over $1 \mathrm{~h}$ was less than 0.0001 mg (400 min for poly(HEA-co-EA) and 1000 min for poly(HEMA-co-MMA)), then 98\% RH until equilibration was reached. Finally, the water uptake of the sample was measured by the sample mass equilibrated at $98 \% \mathrm{RH}$ and $0 \% \mathrm{RH}$ using equation 8 .

Water sorption in a thin polymer membrane can be described by Fick's first law. Assume one dimensional diffusion:

$$
\frac{\partial \mathrm{C}}{\partial t}=D \frac{\partial^{2} \mathrm{C}}{\partial x^{2}}
$$

where $D$ is the average diffusion coefficient of the polymer. The analytical solution given by Crank is:

$$
\frac{\mathrm{M}_{t}}{\mathrm{M}_{\infty}}=1-\frac{8}{\pi^{2}} \sum_{n=0}^{\infty} \frac{1}{(2 n+1)^{2}} \exp \left[-(2 n+1)^{2} \pi^{2} \frac{D t}{L^{2}}\right]
$$

At short times $\left(\mathrm{M}_{t} / \mathrm{M}_{\infty}<0.6\right)$, equation 13 can be written as:

$$
\frac{M_{t}}{M_{\infty}}=\sqrt{\frac{16 D}{\pi L^{2}}} \sqrt{t}
$$

where $M_{t}$ is the mass absorbed by the membrane until time $\mathrm{t}, M_{\infty}$ is the total mass uptake at infinite time [45]. The water diffusion coefficient was determined by the slope of the linear portion of $M_{t} / M_{\infty}\left(M_{t} / M_{\infty}<0.5\right)$ vs $\sqrt{t}$. 
The range of relative humidity values used during the sorption measurements was $93 \%-98 \%$. This range was chosen because it corresponds well with the activity of water in $2 \mathrm{~mol} / \mathrm{L}$ and $0.5 \mathrm{~mol} / \mathrm{L}$ aqueous $\mathrm{NaCl}$ solutions (calculated using the Pitzer model [46]). This agreement was desirable in an effort to characterize water diffusivity in thermodynamic conditions that were representative of the thermodynamic condition during the salt permeation experiment, i.e., we were able to determine water diffusion coefficients by the gravimetric sorption method at water activity values that were similar to those used in the salt permeability measurements $(0.5 \mathrm{~mol} / \mathrm{L})$. Fig. 5 is an example of kinetic water uptake as a function of time.

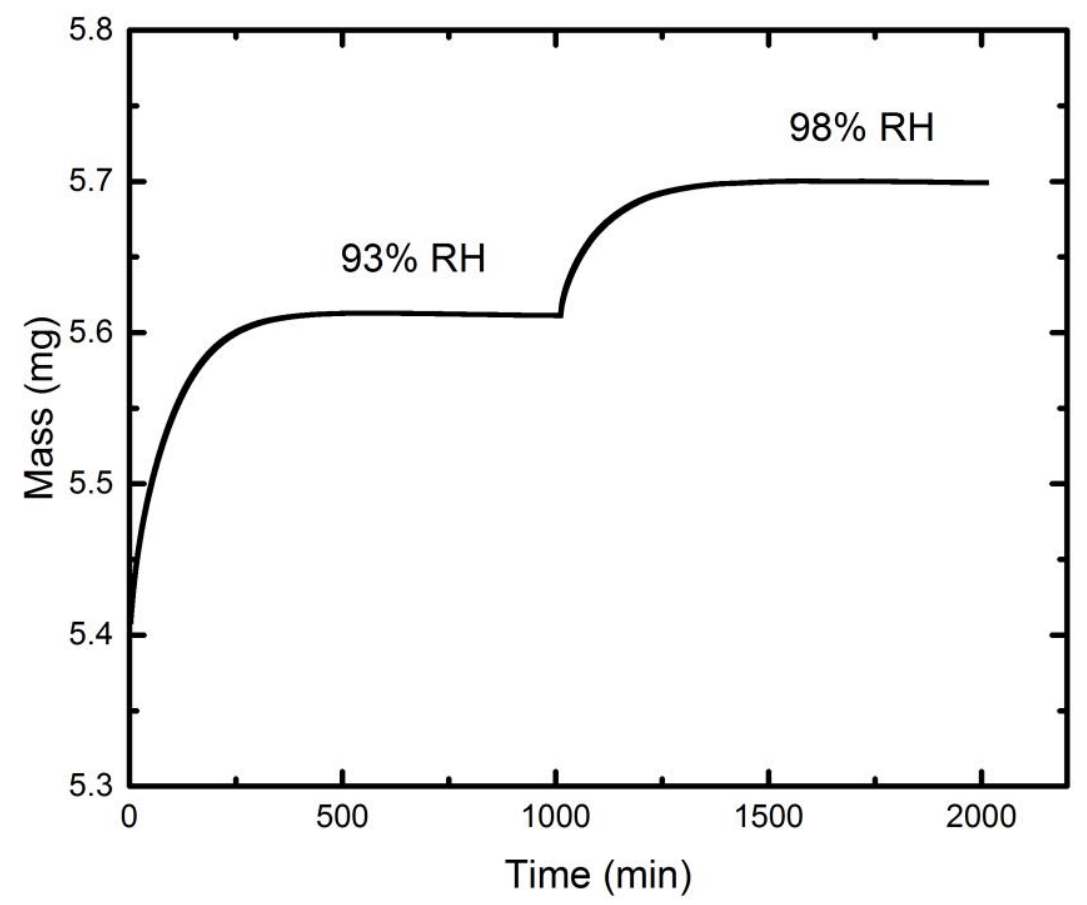

Figure 5 Poly(HEA-CO-EA) 30/70 mass versus time in water sorption process 


\section{Results and discussion}

\subsection{Water sorption}

HEA and HEMA monomers were used to prepare two sets of uncharged hydrophilic polymers for this study. According to free volume theory, water and salt transport properties of polymers are strongly influenced by water uptake, which is often found to be proportional to free volume [40]. Generally, as water uptake increases, the average free volume of polymer increases. Additionally, permeability, diffusivity and solubility properties tend to increase with free volume, and selectivity is predicted to decrease according to the Cohen-Turnbull modeling approach [47]. Diffusivity is related to free volume as follows:

$$
D=a \times \exp \left[-\frac{b}{\left\langle V_{f}\right\rangle}\right]
$$

Equation 4 and 16 yields:

$$
P=K a \times \exp \left[-\frac{b}{\left\langle V_{f}\right\rangle}\right]
$$

where $a$ and $b$ are adjustable parameters and $\left\langle V_{f}\right\rangle$ is average free volume. Since $\left\langle V_{f}\right\rangle$ has been reported to be proportional to water content for several hydrophilic polymers, the influence of water uptake on transport properties must be recognized and controlled [40] [43].

In this study, where we seek to explore the influence of polymer backbone dynamics on transport properties, it is critical to make comparisons between materials at 
equivalent water content. The HEA and HEMA monomers are relatively hydrophilic (see $W_{u}$ of the homopolymers in Table 1) compared to many membrane materials used in desalination applications. As a result, HEA and HEMA monomers were copolymerized with two hydrophobic co-monomers, EA and MMA, respectively, to control the water uptake of the resulting copolymers. As will be discussed in the next section, EA and MMA were selected because they formed miscible pre-polymerization solutions and had similar backbones compared to HEA and HEMA (Table 1).

The water uptake values of poly(HEA-co-EA) and poly(HEMA-co-MMA) films in pure water and $0.5 \mathrm{~mol} / \mathrm{L}$ aqueous sodium chloride solution are reported in Table 2 . By Table 2 Copolymer compositions, density, $W_{u}$ and $K_{w}$ in $0.5 \mathrm{~mol} / \mathrm{L} \mathrm{NaCl}$ and in pure water

\begin{tabular}{|c|c|c|c|c|c|c|}
\hline \multirow[b]{2}{*}{ Copolymer } & \multirow[b]{2}{*}{$\begin{array}{l}\text { Composition } \\
\text { (wt } \%)\end{array}$} & \multirow{2}{*}{$\begin{array}{l}\text { Density of } \\
\text { dry polymer } \\
\left(\mathrm{g} / \mathrm{cm}^{3}\right)\end{array}$} & \multicolumn{2}{|c|}{ Water content in $0.5 \mathrm{~mol} / \mathrm{L} \mathrm{NaCl}$} & \multicolumn{2}{|c|}{ Water content in pure water } \\
\hline & & & $\begin{array}{c}W_{u} \\
{\left[\mathrm{~g}\left(\mathrm{H}_{2} \mathrm{O}\right) / \mathrm{g}(\mathrm{dry}\right.} \\
\text { polymer })]\end{array}$ & $K_{w}$ & $\begin{array}{c}W_{u} \\
{\left[\mathrm{~g}\left(\mathrm{H}_{2} \mathrm{O}\right) / \mathrm{g}(\mathrm{dry}\right.} \\
\text { polymer })]\end{array}$ & $K_{w}$ \\
\hline \multirow{3}{*}{$\begin{array}{c}\text { Poly(HEA- } \\
\text { co-EA) }\end{array}$} & $30 / 70$ & $1.20 \pm 0.01$ & $0.073 \pm 0.005$ & $0.080 \pm 0.005$ & $0.081 \pm 0.005$ & $0.089 \pm 0.006$ \\
\hline & $35 / 65$ & $1.20 \pm 0.01$ & $0.082 \pm 0.004$ & $0.090 \pm 0.005$ & $0.091 \pm 0.005$ & $0.098 \pm 0.006$ \\
\hline & $40 / 60$ & $1.22 \pm 0.01$ & $0.102 \pm 0.008$ & $0.111 \pm 0.008$ & $0.106 \pm 0.006$ & $0.115 \pm 0.007$ \\
\hline \multirow{3}{*}{$\begin{array}{c}\text { Poly(HEMA } \\
\text {-co-MMA) }\end{array}$} & $30 / 70$ & $1.22 \pm 0.01$ & $0.086 \pm 0.004$ & $0.095 \pm 0.005$ & $0.091 \pm 0.005$ & $0.099 \pm 0.006$ \\
\hline & $35 / 65$ & $1.23 \pm 0.01$ & $0.091 \pm 0.005$ & $0.101 \pm 0.006$ & $0.098 \pm 0.003$ & $0.107 \pm 0.004$ \\
\hline & $40 / 60$ & $1.25 \pm 0.02$ & $0.115 \pm 0.003$ & $0.126 \pm 0.004$ & $0.118 \pm 0.007$ & $0.129 \pm 0.008$ \\
\hline
\end{tabular}

varying the composition of hydrophilic and hydrophobic monomers, overlap in the water uptake of the samples was achieved. Water uptake values were less than 0.2 $\mathrm{g}($ water $) / \mathrm{g}$ (dry polymer). These polymers sorb relatively little water compared to highly hydrated ion exchange or hydrogel materials, but they sorb amounts of water that are 
comparable to the extent of water sorption in polyamide $(<0.2, \mathrm{~g}($ water $) / \mathrm{g}$ (wet polymer) or cellulose acetate membrane polymers $(0.15 \mathrm{~g}($ water $) / \mathrm{g}($ dry polymer $))$ used in commercial desalination membranes [48][49]. Water uptake values and water sorption coefficients of the two copolymers increase with increasing mass fraction of hydrophilic monomer. Additionally, the water uptake in pure water is greater than that in salt solution due to the phenomenon known as osmotic de-swelling [3].

\subsection{Salt sorption}

Another requirement for the polymers used in this study is that the materials should have similar chemistry such that differences in salt sorption between the polymers are minimized. Salt sorption in uncharged polymers is expected to be primarily dependent on water uptake and polymer chemistry. Therefore, preparing polymers with similar chemical structure was expected to result in similar salt sorption properties between the two materials. The chemistry of the polymers used in this study is relatively similar (Table 1). Sodium chloride sorption coefficient data for poly(HEA-co-EA) and poly(HEMA-co-MMA) overlap as a function of water uptake (Fig. 6). Therefore, the chemical environment of the two copolymers is similar to the point where sorption properties appear to be unaffected by the differences in chemical structure. This situation allows us to attribute differences in transport properties between the two copolymers (at 
equivalent water uptake) to diffusive processes (such as polymer backbone dynamics) while minimizing the influence of sorption effects on transport properties.

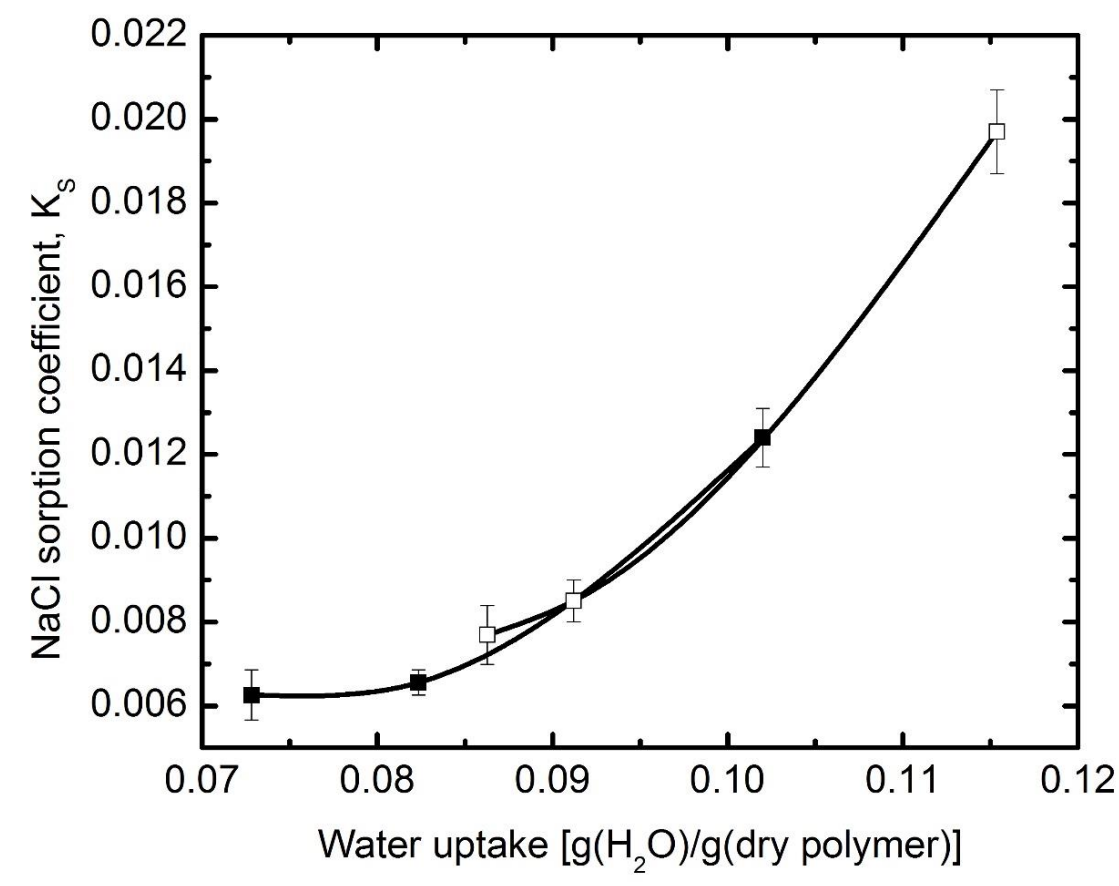

Figure 6 Sodium chloride sorption coefficients of poly(HEA-Co-EA) ( $\square)$ and poly(HEMA-co-MMA) ( $\square$ ) as a function of water uptake in $0.5 \mathrm{~mol} / \mathrm{L} \mathrm{NaCl}$ solution

\subsection{Backbone dynamics characterization}

Segments along a polymer chain are dynamic, and segmental relaxation dynamics are thermally stimulated [50]. The chemical structure of the polymer and interactions between chains often play a key role in determining the rigidity or flexibility (low or high segmental mobility) of the backbone [50]. Poly(HEA-co-EA) and poly(HEMA-co-MMA) were selected because poly(methacrylates) have methyl groups on the backbone that increase the energy barrier for segmental motion compared with 
poly(acrylates). As a result, poly(HEMA-co-MMA) is expected to have a more rigid backbone compared to poly(HEA-co-EA).

Segmental dynamics in polymers can be characterized by glass transition temperature (Tg) as Tg marks the temperature above which segmental dynamics are fast enough to allow the polymer chains to achieve equilibrium conformation [50]. Below $\mathrm{Tg}$, segmental motion is slowed to the point where polymer chains are kinetically trapped in non-equilibrium states that slowly relax toward equilibrium via the process known as physical aging [51].

A homogeneous polymer, where the monomers are well mixed, is expected to have a single $\mathrm{Tg}$ [52]. The $\mathrm{Tg}$ value of the blend typically falls between the glass transition temperatures of the two homopolymer components. The glass transition temperature of a miscible binary polymer blend can be estimated by the Fox equation:

$$
\frac{1}{T_{g, \text { blends }}}=\frac{\omega_{1}}{T_{g 1}}+\frac{\omega_{2}}{T_{g 2}}
$$

where $\omega_{i}$ is mass fractions of components $i$ [52]. Table 3 shows the Tg of dry polymers predicted by Fox equation. Water can act as a plasticizer, which interrupts the polymer matrix and lowers the Tg. As a result, the Tg of hydrated polymers should be measured. 
Table $3 \mathrm{Tg}$ of dry copolymers estimated by Fox equation.

\begin{tabular}{ccc}
\hline \multirow{2}{*}{ Composition } & poly(HEA-co-EA)/ & poly(HEMA-co-MMA)/ \\
& ${ }^{\circ} \mathrm{C}$ & ${ }^{\circ} \mathrm{C}$ \\
\hline $30 / 70$ & -13 & 100 \\
$35 / 65$ & -12 & 97 \\
$40 / 60$ & -10 & 94 \\
\hline
\end{tabular}

The DSC thermograms in Fig. 7 show that the glass transition temperatures of hydrated poly(HEMA-co-MMA) films are greater than of poly(HEA-co-EA). This result is consistent with our expectation that the poly(HEMA-co-MMA) backbone is more rigid than the poly(HEA-co-EA) backbone.

The copolymers all exhibit single glass transition temperatures. Copolymer with compositions closer to 50/50 were observed, in some cases, to have two distinct $\mathrm{Tg}$ values. This result suggests that these copolymers are relatively homogeneous materials without appreciable phase separation. The DSC results suggest that, poly(HEA-co-EA) films are rubbery and poly(HEMA-co-MMA) films are glassy at experimental conditions $\left(25^{\circ} \mathrm{C}\right.$, hydrated state). 


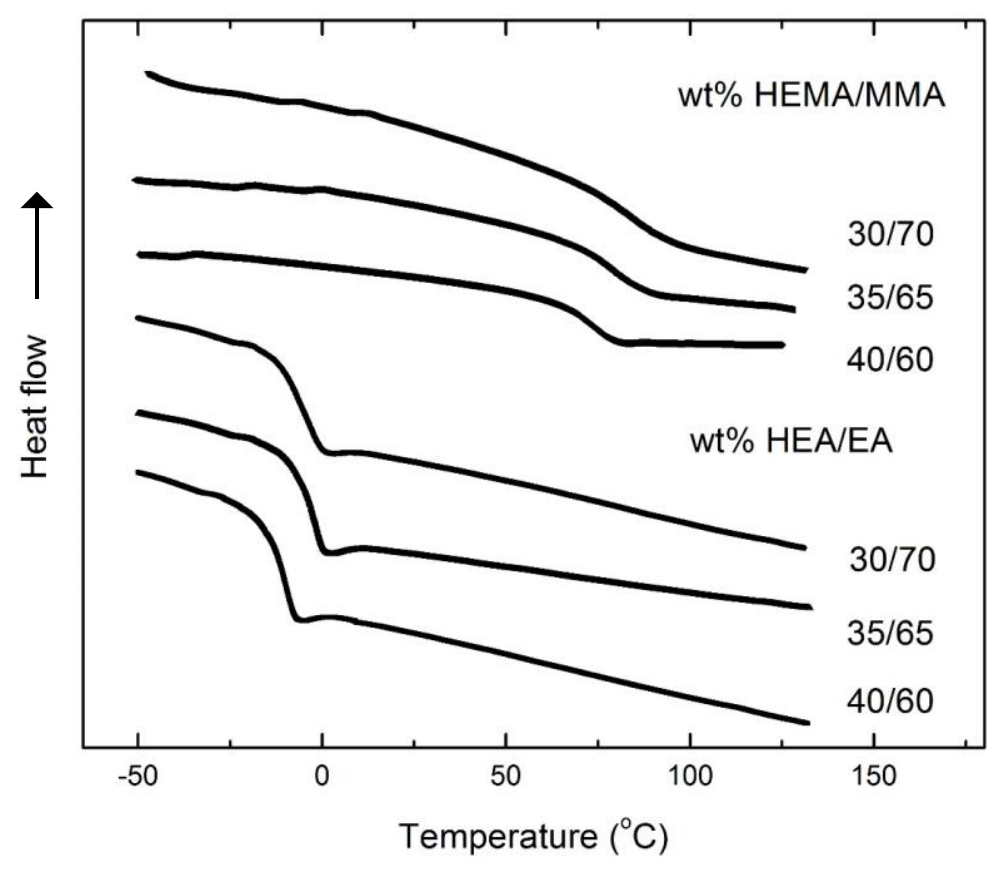

Figure 7 DSC thermograms for hydrated poly(HEMA-co-MMA) and poly(HEA-co-EA) at different compositions. The thermograms were displaced vertically for clarity.

\subsection{Water/salt transport characterization}

Since poly(HEA-co-EA) and poly(HEMA-co-MMA) met all of the abovementioned material characteristics, we characterized and compared their transport properties. The salt permeability values of the poly(HEA-co-EA) and poly(HEMA-co-MMA) polymers increase with increasing water content as expected based on theory and previous studies (Fig. 8) [43][53]. The more flexible backbone poly(HEA-co-EA) polymer exhibits greater permeability at equivalent water uptake compared to the more rigid backbone poly(HEMA-co-MMA). These results suggest that polymer chain dynamics influence salt permeability. In general, more rigid polymers tend 
to slow down dynamics within the hydrated polymer while more flexible polymers tend to permit faster dynamics within the hydrated polymer, and the permeability values follow these trends.

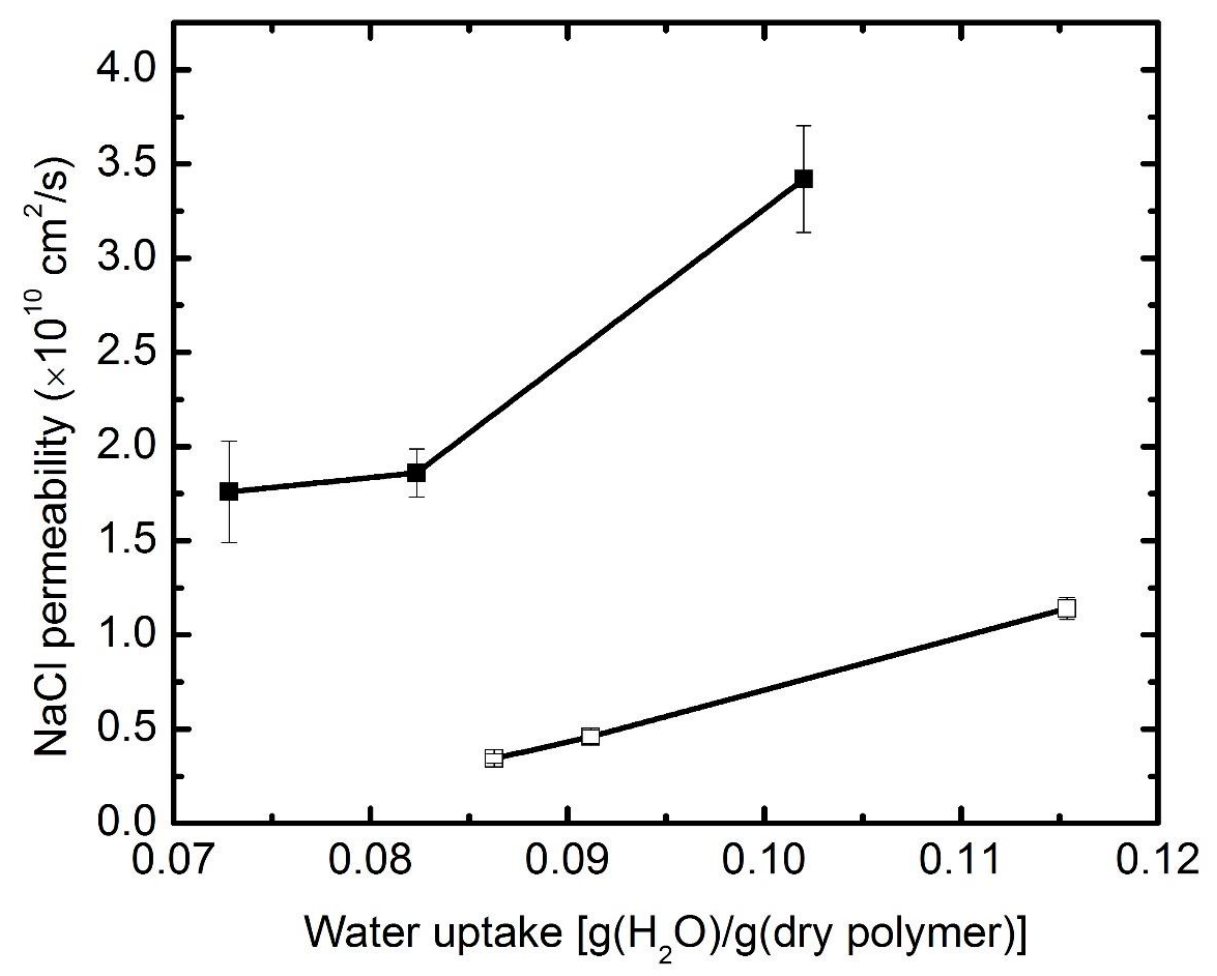

Figure 8 Salt permeability for poly(HEA-Co-EA) ( $\square$ ) and poly(HEMA-co-MMA) ( $\square$ ) as a function of water uptake in $0.5 \mathrm{~mol} / \mathrm{L} \mathrm{NaCl}$ solution

The average salt diffusivity can be calculated from measurements of salt sorption and permeability coefficients. Average water diffusivity values were measured by gravimetric sorption studies. Fig. 9 compares the water and $\mathrm{NaCl}$ diffusion coefficients calculated using equation 4 in the copolymers. The diffusion coefficients in poly(HEMA-co-MMA) are lower than in poly(HEA-co-EA), which can be ascribed to 
the slow dynamics of the poly(HEMA-co-MMA) rigid backbone. The polymer chains move constantly due to thermal stimulation, and free volume in the polymer matrix, which can be occupied by water molecules and ions, redistributes during chain motion. Therefore, it is reasonable to expect that flexible polymers would exhibit greater diffusivity compared to rigid polymers.

a

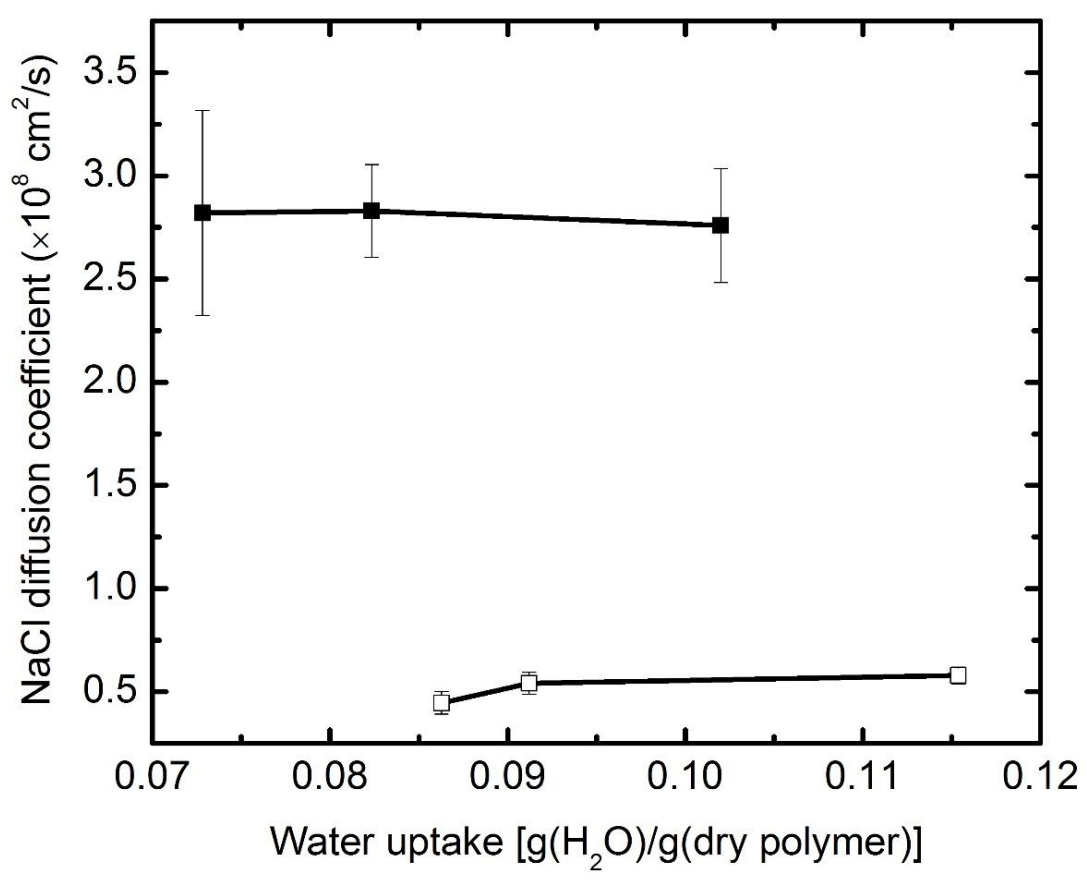




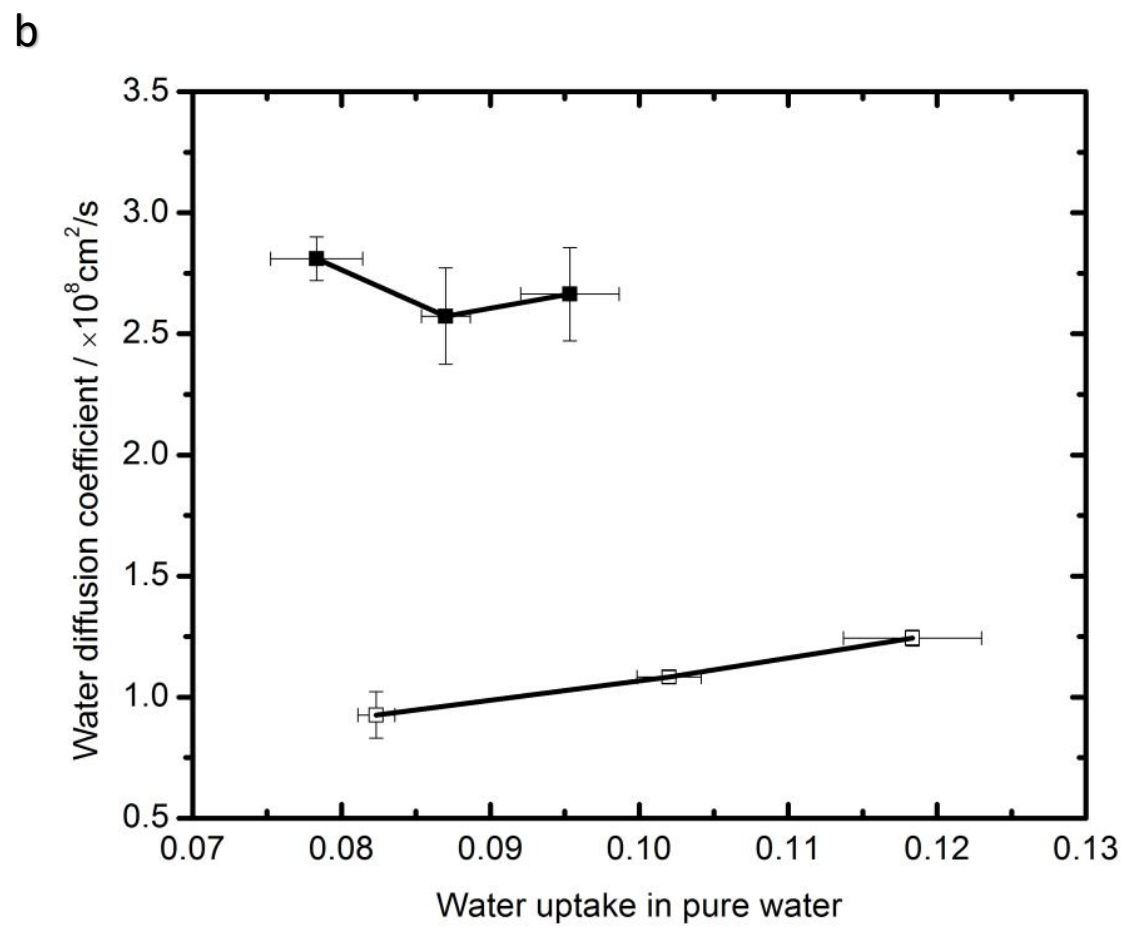

Figure $9 \mathrm{NaCl}$ diffusivity as a function of water uptake in $0.5 \mathrm{~mol} / \mathrm{L} \mathrm{NaCl}$ solution (a) and water diffusivity as a function of water uptake in pure water (b) for poly (HEA-co-EA) ( $\square)$ and poly (HEMA-Co-MMA) ( $\square)$

Fig. 10 exhibits the sorption selectivity, $K_{w} / K_{s}$, as a function of water sorption coefficient. A tradeoff relationship between the water sorption coefficient and sorption selectivity is observed in these copolymers. Fig. 11 presents the sorption selectivity versus $K_{w}$ in many polymers of interest for desalination. It is noteworthy to point out that poly(HEMA-co-MMA) and poly(HEA-co-EA) have relatively high sorption selectivity compared to other polymers of equivalent water content, which is desired in desalination membranes. 


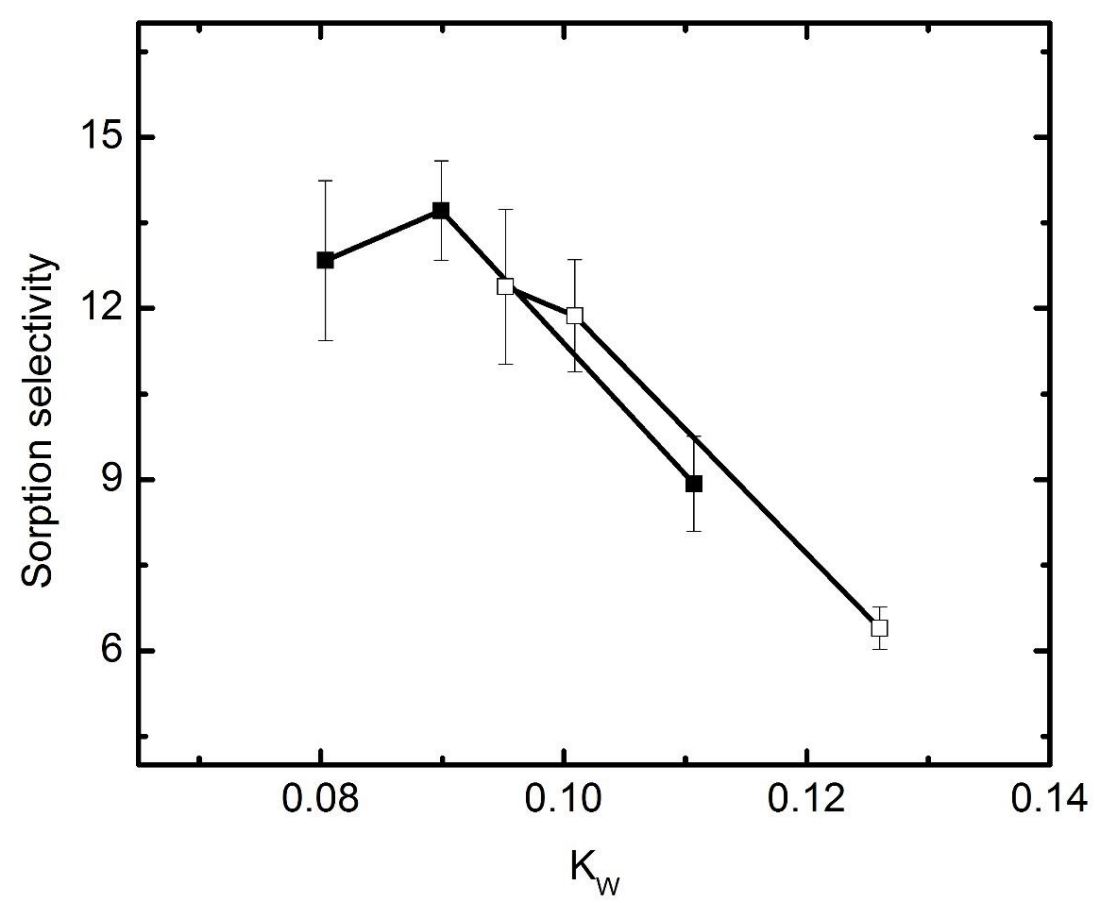

Figure 10 Sorption selectivity for poly(HEA-co-EA) ( $\square$ ) and poly(HEMA-co-MMA) ( $\square$ ) versus water sorption coefficient in $0.5 \mathrm{~mol} / \mathrm{L} \mathrm{NaCl}$ solution

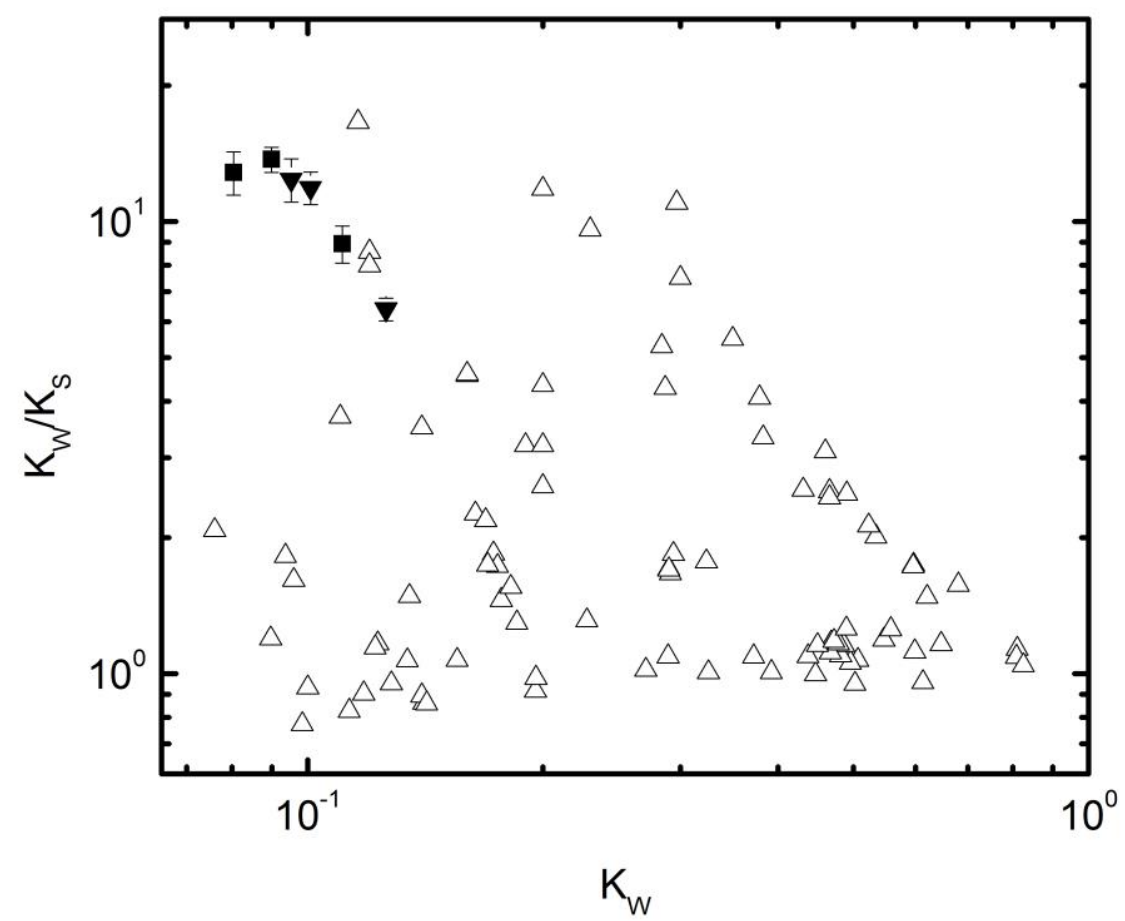

Figure 11 Sorption selectivity $K_{w} / K_{s}$ versus water sorption coefficient $K_{w}$ for poly(HEA co EA) ( $\boldsymbol{\square})$, poly (HEMA-co-MMA) ( $\boldsymbol{\nabla})$ and a variety of polymers reported in the literature ( $\triangle$ ) [3]. 
As shown in Fig. 10, the sorption selectivity does not appear to be significantly dependent on the backbone rigidity. The water/salt diffusion selectivity, $D_{w} / D_{s}$, of poly(HEMA-co-MMA), however, is greater than that of poly(HEA-co-EA) (Fig. 12). This result is consistent with results from the gas separation literature [31]. These results support the view that polymer backbone dynamics influence the diffusion selectivity of a material and thereby the permeability selectivity. The rigid polymer is more selective, which can be ascribed to the effect of opening and closing of transient gaps within the polymer during the diffusion process [54]. Furthermore, the slower dynamics of the poly(HEMA-co-MMA) system could influence water molecule dynamics in the polymer via hydrogen bonding, and a reduction in water molecule rotational dynamics would be consistent with a lower dielectric constant and enhanced sorption selectivity, which is consistent with the sorption selectivity results reported in Fig. 10.

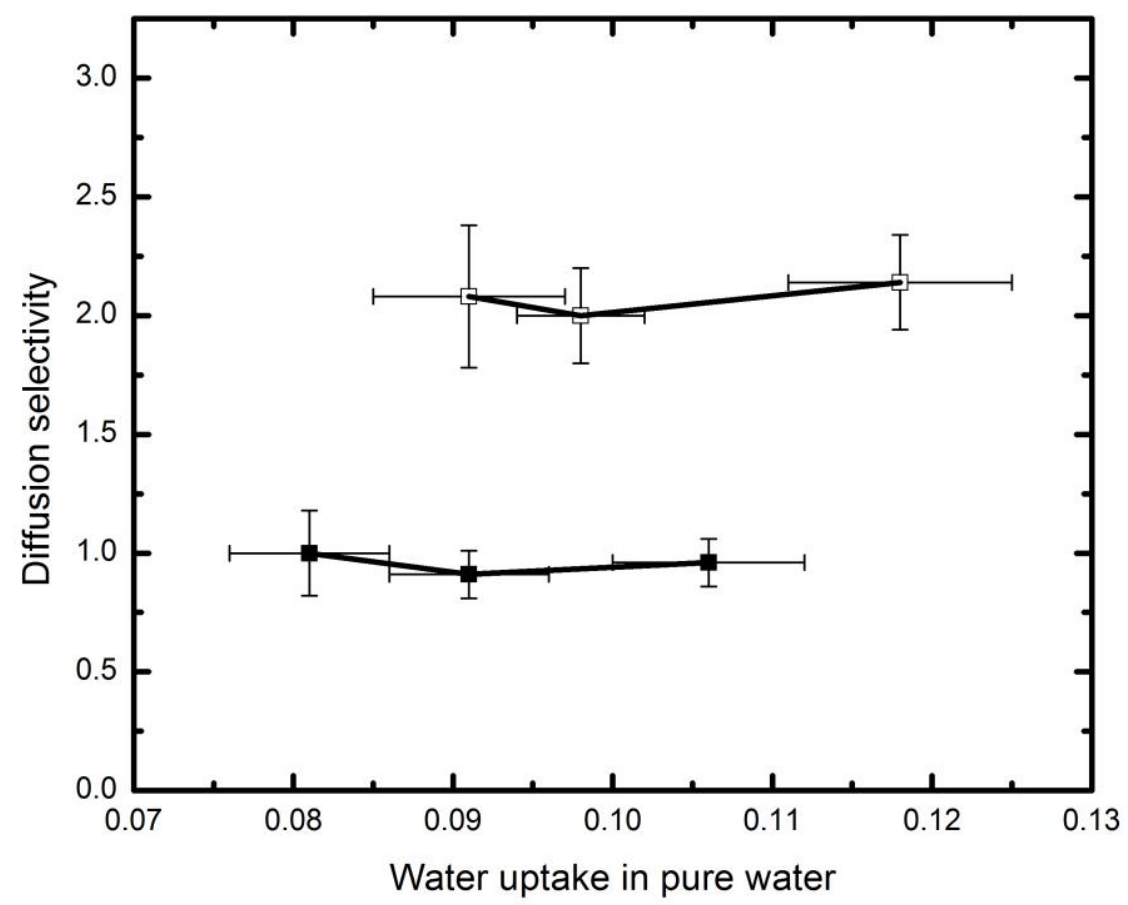

Figure 12 Diffusion selectivity, $D_{w} / D_{s}$, for poly(HEA-co-EA) ( $\square$ ) and poly (HEMA-co-MMA) 
The diffusion coefficients of water and sodium chloride for poly(HEA-co-EA) are approximately the same, which is not often observed in water/ion transport in polymers. One possibility is that a vapor phase water diffusion boundary layer exists such that the gas/membrane interface mass transfer resistance is not negligible.

To examine whether the interface mass transfer resistance is important, water diffusion coefficients were measured at $150 \mathrm{~mL} / \mathrm{min}$ and $200 \mathrm{~mL} / \mathrm{min}$ gas flow rates. Results are compared in Table 4. When the gas flow rate is relatively high, the mass transfer resistance in the boundary layer should be reduced. Table 4 shows that $D_{w}$ does not vary much as gas flow rate increases, which suggests that water diffusion in membrane is rate limiting and mass transfer in boundary layer is relatively fast.

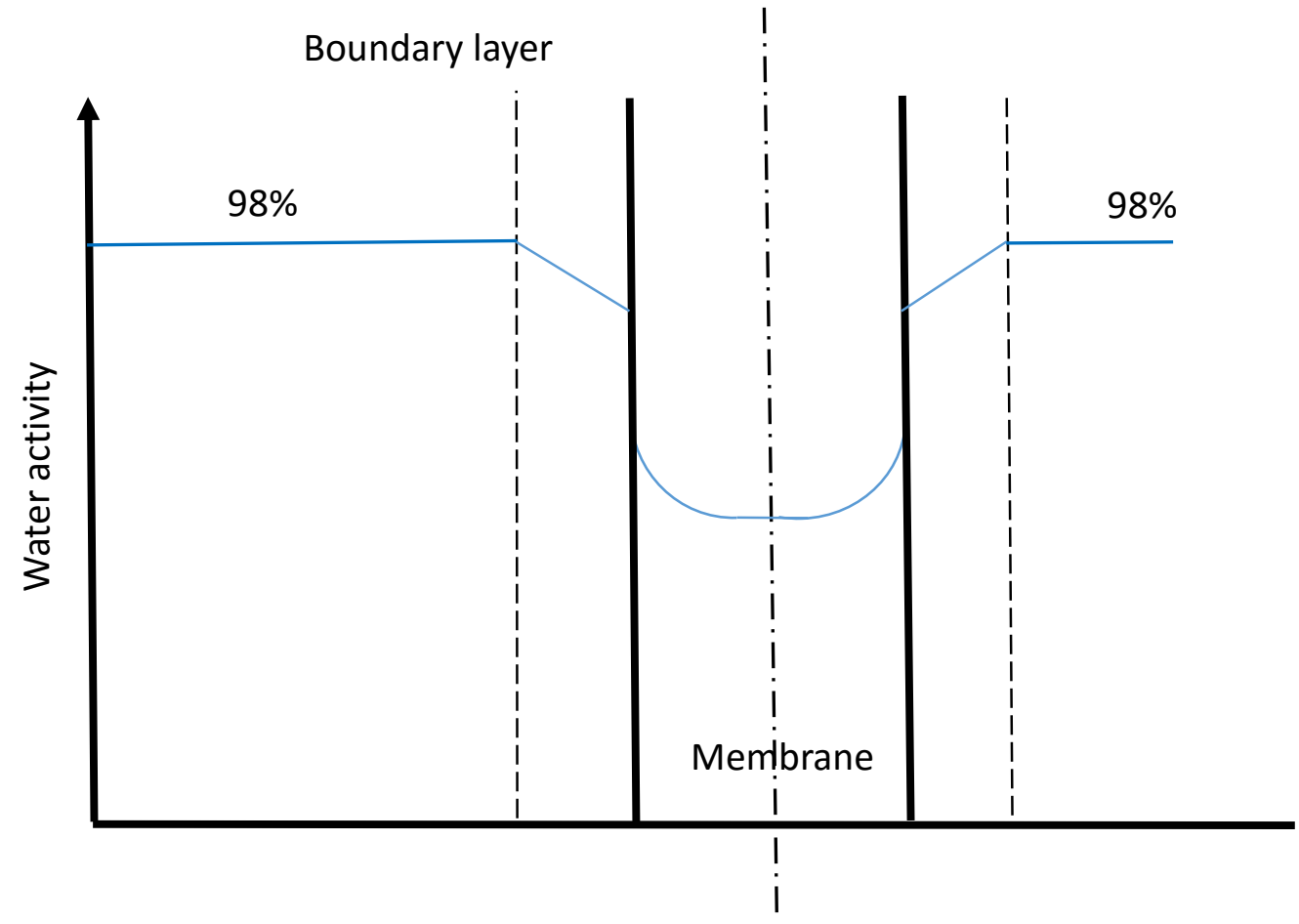

Figure 13 Schematic of simplified water activity profile in a dynamic sorption process 
Table $4 D_{w}$ of a 40/60 poly(HEMA-co-MMA) at 150 and $200 \mathrm{~mL} / \mathrm{min}$ gas flow rates

\begin{tabular}{cc}
\hline $\begin{array}{c}\text { Gas flow rate } \\
/ \mathrm{mL} / \text { min }\end{array}$ & $\begin{array}{c}\mathrm{D}_{\mathrm{w}} \text { of } \\
\text { poly(HEMA-co-MMA) } \\
/ \times 10^{8} \mathrm{~cm}^{2} / \mathrm{s}\end{array}$ \\
\hline 150 & 1.27 \\
200 & 1.39 \\
\hline
\end{tabular}

Since the boundary layer effects should be the smallest near the end of the sorption process (as the concentration difference between the bulk vapor and membrane phase will be minimized), the water diffusion coefficient was solved in the range of $M_{t} / M_{\infty}=0.6 \sim 0.9$ (Fig. 14) using the analytical solution (equation 14) assuming stagnant flow field for simplicity. The value of $D_{w}$ at $M_{t} / M_{\infty} \rightarrow 1,1.6 \times 10^{-8} \mathrm{~cm}^{2} / \mathrm{s}$, is $30 \%$ greater than the value regressed using short time data and equation 15 . Thus, these data suggest that boundary layer effects may not be particularly significant in this system.

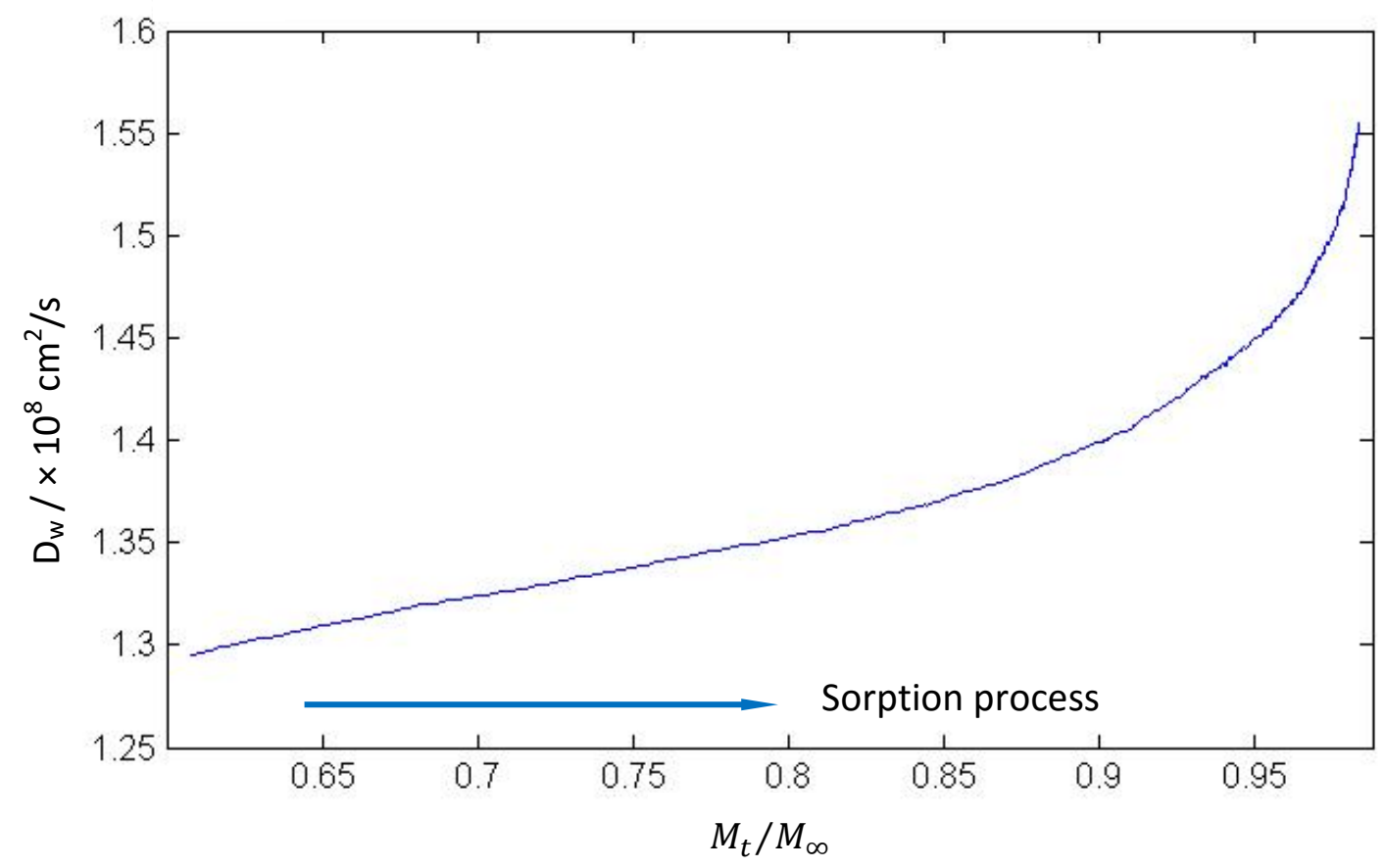

Figure $14 D_{w}$ of a 40/60 poly(HEMA-co-MMA) near the end of sorption versus $M_{t} / M_{\infty}$ 
Another possibility is that unhydrated ions exist in poly(HEA-co-EA) due to its low water content and hydrophilic nature [55]. Unhydrated ions may diffuse faster than water molecules. We can further probe the water motion in polymers using pulsed gradient NMR to determine water self-diffusion coefficient through water relaxation properties.

\subsection{Effect of penetrant size on selectivity}

As shown in Fig. 15, the diffusion coefficient for a variety of gases decreases with increasing gas molar volume in gas separation membranes [31]. In addition, diffusion coefficients in a polymer with a rigid backbone decreases faster with increasing penetrant size indicating they are size selective compared to a flexible backbone polymer. To further investigate the effect of backbone dynamics on size selectivity, transport properties of three binary chlorides, $\mathrm{KCl}, \mathrm{NaCl}$ and $\mathrm{LiCl}$ were determined. The hydrated radii of the cations are listed in Table 5, and $r_{\mathrm{K}^{+}}<r_{\mathrm{Na}^{+}}<r_{\mathrm{Li}^{+}}$. 


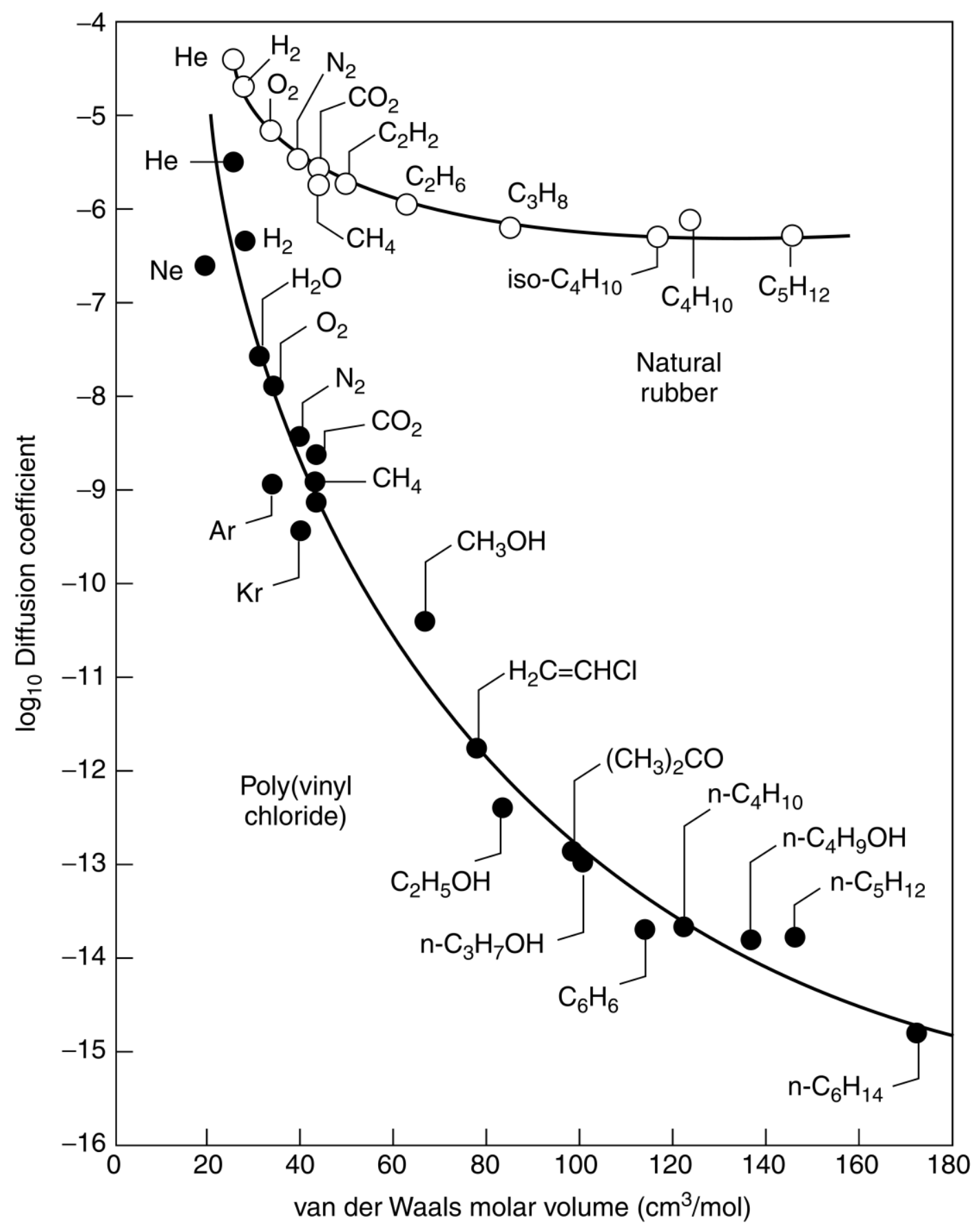

Figure 15 Diffusion coefficients for a variety of gases as a function of molar volume in flexible (natural rubber) and rigid (poly(vinyl chloride)) polymers [31] 
Table 5 Hydrated radii at $25^{\circ} \mathrm{C}[56]$

\begin{tabular}{cc}
\hline Ion & Hydrated radii/Å \\
\hline $\mathrm{K}^{+}$ & 3.31 \\
$\mathrm{Na}^{+}$ & 3.58 \\
$\mathrm{Li}^{+}$ & 3.82 \\
\hline
\end{tabular}

Since diffusivities of both ions contribute to the overall diffusivity of a salt, the size of a salt can be characterized using its average diffusion coefficient at infinite dilution, which is determined as:

$$
D_{\text {salt }}=\frac{\left(z_{+}+\left|z_{-}\right|\right) D_{+} D_{-}}{z_{+} D_{+}+\left|z_{-}\right| D_{-}}
$$

where $D_{+}$and $D_{-}$are the diffusion coefficients of ions at infinite dilution. $z_{+}=\left|z_{-}\right|=$ 1 for sodium, potassium and lithium chloride.

Table 6 shows the average diffusion coefficients of $\mathrm{KCl}, \mathrm{NaCl}$ and $\mathrm{LiCl}$ calculated by ion diffusion coefficients at infinite dilution, $D_{K C l}>D_{N a C l}>D_{L i C l}$. As expected, diffusion coefficient of $\mathrm{KCl}$ is greater than other salts since the hydrated radius of potassium is smaller.

Table 6 Average diffusion coefficients of $\mathrm{KCl}, \mathrm{NaCl}$ and $\mathrm{LiCl}$ at infinite dilution

\begin{tabular}{cccc}
\hline Salt & $D_{+} / \times 10^{-5} \mathrm{~cm}^{2} / \mathrm{s}[57]$ & $D_{-} / \times 10^{-5} \mathrm{~cm}^{2} / \mathrm{s}[57]$ & $D_{\text {salt }} / \times 10^{-5} \mathrm{~cm}^{2} / \mathrm{s}$ \\
\hline $\mathrm{KCl}$ & 1.957 & 2.032 & 1.99 \\
$\mathrm{NaCl}$ & 1.334 & 2.032 & 1.61 \\
$\mathrm{LiCl}$ & 1.029 & 2.032 & 1.37 \\
\hline
\end{tabular}


Water uptake of poly(HEA-co-EA) and poly(HEMA-co-MMA) in $\mathrm{KCl}, \mathrm{LiCl}$ and

$\mathrm{NaCl}$ are shown in Table 7. For both copolymers, the water uptake values in different salt solutions are similar.

Table $7 \mathrm{~W}_{\mathrm{u}}$ in $0.5 \mathrm{~mol} / \mathrm{L} \mathrm{KCl,} \mathrm{NaCl}$ and $\mathrm{LiCl}$

\begin{tabular}{ccccc}
\hline Copolymer & $\begin{array}{c}\text { Composition(wt } \\
\%)\end{array}$ & $\begin{array}{c}\text { Wu in NaCl} \\
{\left[\mathrm{g}\left(\mathrm{H}_{2} \mathrm{O}\right) / \mathrm{g}(\mathrm{dry}\right.} \\
\text { polymer })\end{array}$ & $\begin{array}{c}\text { Wu in } \mathrm{KCl} \\
{\left[\mathrm{g}\left(\mathrm{H}_{2} \mathrm{O}\right) / \mathrm{g}(\mathrm{dry}\right.} \\
\text { polymer })\end{array}$ & $\begin{array}{c}\text { Wu in } \mathrm{LiCl} \\
{\left[\mathrm{g}\left(\mathrm{H}_{2} \mathrm{O}\right) / \mathrm{g}(\mathrm{dry}\right.} \\
\text { polymer })\end{array}$ \\
\hline $\begin{array}{c}\text { Poly(HEA co } \\
\text { EA) }\end{array}$ & $30 / 70$ & $0.073 \pm 0.005$ & $0.070 \pm 0.005$ & $0.072 \pm 0.002$ \\
& $35 / 65$ & $0.082 \pm 0.004$ & $0.081 \pm 0.002$ & $0.088 \pm 0.007$ \\
\hline $\begin{array}{c}\text { Poly(HEMA co } \\
\text { MMA) }\end{array}$ & $30 / 60$ & $0.102 \pm 0.008$ & $0.102 \pm 0.004$ & $0.104 \pm 0.008$ \\
\hline & $35 / 65$ & $0.086 \pm 0.004$ & $0.085 \pm 0.004$ & $0.083 \pm 0.002$ \\
& $40 / 60$ & $0.091 \pm 0.005$ & $0.090 \pm 0.007$ & $0.091 \pm 0.003$ \\
& $0.115 \pm 0.003$ & $0.109 \pm 0.006$ & $0.111 \pm 0.004$ \\
\hline
\end{tabular}

Permeability selectivity of sodium/potassium chloride and lithium/potassium chloride for poly(HEMA-co-MMA) and poly(HEA-co-EA) were determined as:

$$
\alpha_{i / K C l}=\frac{P_{i}}{P_{K C l}}
$$


where $i$ is $\mathrm{NaCl}$ or $\mathrm{LiCl}$.

Fig. 16 compares the salt permeability selectivity of the copolymers as a function of salt average diffusion coefficient, which characterizes the size of salt. Penetrant size increases from left to right and salt average diffusion coefficient decreases in Fig. 16. The compositions of the copolymers in $\mathrm{NaCl} / \mathrm{KCl} / \mathrm{LiCl}$ permeability measurements are roughly $30 / 70$ to prepare polymers with similar water uptake. The water uptake of poly(HEMA-co-MMA) samples in $0.5 \mathrm{M} \mathrm{NaCl}$ is $0.078 \pm 0.003$ and $W_{u}$ of poly(HEA-co-EA) is $0.074 \pm 0.003$. Selectivity of both $\mathrm{Na} / \mathrm{K}$ and $\mathrm{Li} / \mathrm{K}$ for poly(HEMA-co-MMA) is greater than that for poly(HEA-co-EA), which is consistent

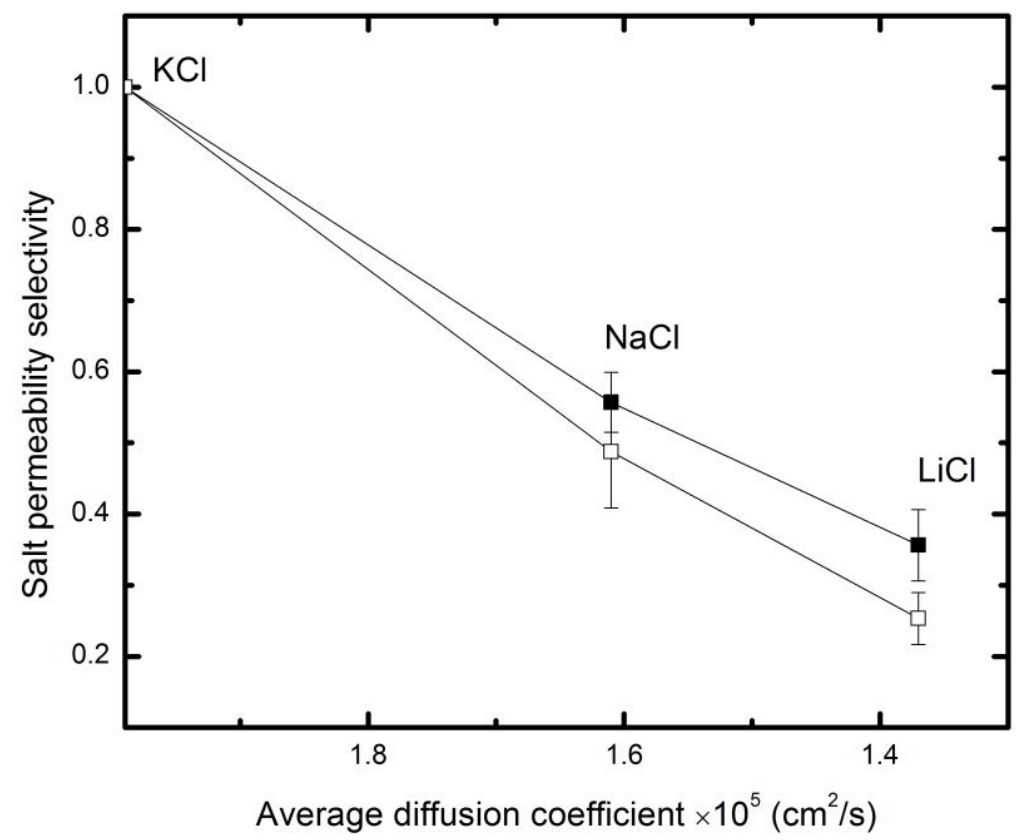

Figure $16 \mathrm{NaCl} / \mathrm{KCl}, \mathrm{LiCl} / \mathrm{KCl}$ and $\mathrm{KCl} / \mathrm{KCl}$ permeability selectivity for poly(HEA-Co-EA) ( $\square$ ) and poly(HEMA-co-MMA) ( $\square$ ) versus average diffusion coefficient (infinite dilution). Water uptake of poly(HEA-co-EA) and poly(HEMA-Co-MMA) in $0.5 \mathrm{M} \mathrm{NaCl}$ are $0.074 \pm 0.003$ and $0.078 \pm 0.003$, respectively. 
with the results from the water/salt transport studies. As penetrant size increases, the influence of polymer backbone dynamics on selectivity increases.

Table 8 reports the sorption coefficients in half molar $\mathrm{KCl} / \mathrm{NaCl} / \mathrm{LiCl}$ solutions. Changing the cation does not significantly influence the sorption behavior of both poly(HEA-co-EA) and poly(HEMA-co-MMA) films.

Table 8 Sorption coefficients in $0.5 \mathrm{~mol} / \mathrm{L} \mathrm{NaCl}, \mathrm{KCl}$ and $\mathrm{LiCl}$

\begin{tabular}{ccccc}
\hline Copolymer & $\begin{array}{c}\text { Composition } \\
(\text { wt } \%)\end{array}$ & Ks in $0.5 \mathrm{M} \mathrm{NaCl}$ & $\mathrm{Ks} \mathrm{in} 0.5 \mathrm{M} \mathrm{KCl}$ & Ks in 0.5 M LiCl \\
\hline & $30 / 70$ & $0.0063 \pm 8.9 \%$ & $0.0062 \pm 3.7 \%$ & $0.0063 \pm 6.0 \%$ \\
$\begin{array}{c}\text { Poly(HEA co } \\
\text { EA })\end{array}$ & $35 / 65$ & $0.0066 \pm 4.0 \%$ & $0.0075 \pm 5.3 \%$ & $0.0070 \pm 2.9 \%$ \\
& $40 / 60$ & $0.0124 \pm 5.5 \%$ & $0.0131 \pm 5.3 \%$ & $0.0130 \pm 4.6 \%$ \\
\hline & $30 / 70$ & $0.0077 \pm 9.6 \%$ & $0.0073 \pm 7.7 \%$ & $0.0080 \pm 8.4 \%$ \\
$\begin{array}{c}\text { Poly(HEMA co } \\
\text { MMA })\end{array}$ & $35 / 65$ & $0.0085 \pm 5.8 \%$ & $0.0077 \pm 8.5 \%$ & $0.0084 \pm 4.3 \%$ \\
& $40 / 60$ & $0.0197 \pm 5.0 \%$ & $0.0194 \pm 9.9 \%$ & $0.0190 \pm 2.8 \%$ \\
\hline
\end{tabular}

The diffusivity selectivity of $\mathrm{Na} / \mathrm{K}$ and $\mathrm{Li} / \mathrm{K}$ as a function of average diffusion coefficient are shown in Fig. 17. Increasing polymer backbone rigidity increases salt diffusivity selectivity. 


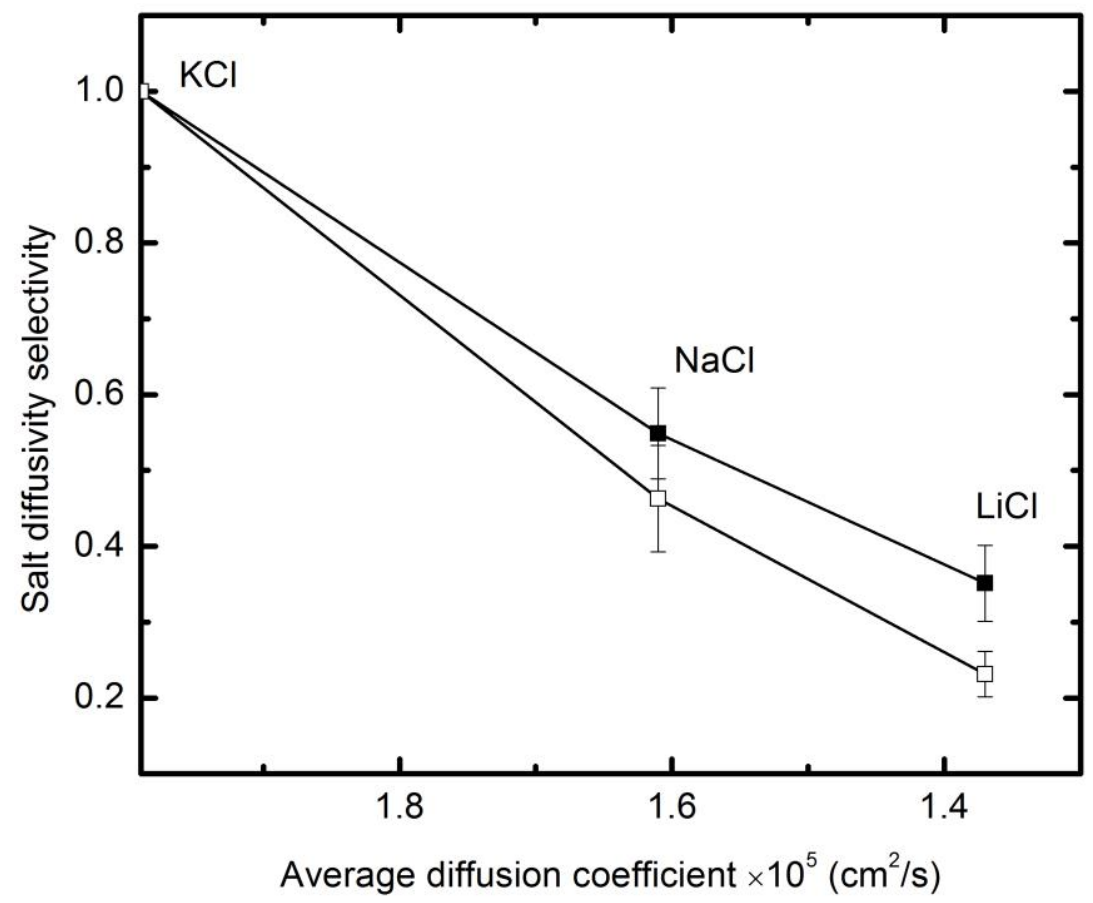

Figure $17 \mathrm{NaCl} / \mathrm{KCl}, \mathrm{LiCl} / \mathrm{KCl}$ and $\mathrm{KCl} / \mathrm{KCl}$ diffusion selectivity for poly(HEA-CO-EA) ( $\mathbf{\square})$ and poly(HEMA-co-MMA) ( $\square$ ) versus average diffusion coefficient. Water uptake of poly(HEA-co-EA) and poly(HEMA-co-MMA) in $0.5 \mathrm{M} \mathrm{NaCl}$ are $0.074 \pm 0.003$ and $0.078 \pm 0.003$, respectively.

It should be pointed out that the range of penetrant size in this work, $\mathrm{KCl}-\mathrm{LiCl}$, is smaller than the gas penetrant size range in Fig. 15. The effect of polymer backbone dynamics was not distinct for $\mathrm{NaCl}$. However, significant difference of diffusion selectivity was observed for $\mathrm{LiCl}$. In future work, larger penetrants such as $\mathrm{NH}_{4} \mathrm{Cl}$ should be tested to expand the penetrant size range and further verify the influence of backbone dynamics. 


\title{
4. Conclusions and recommendations
}

\author{
Water/ion transport properties and backbone rigidity of two homogeneous \\ uncharged copolymers, poly(HEMA-co-MMA) and poly(HEA-co-EA) were \\ characterized to evaluate the effect of polymer backbone dynamics on water and salt \\ transport. The composition of the co-monomers was adjusted to control the water uptake \\ of the resulting copolymers so that the influence of water uptake and free volume was \\ controlled in these experiments.
}

Polymers were chosen to have similar chemistry, and as a result, salt sorption properties of the copolymers were unaffected by changing the backbone rigidity. Water and salt diffuse faster in flexible polymers, and the rigid polymer is more size selective compared to the flexible backbone polymer. These results support the view that increasing polymer backbone rigidity can increase the water/salt selectivity of uncharged polymers provided that other variables are controlled and the water content of the polymer is sufficiently low such that chain dynamics become important. As cation size increases, salt permeability and diffusivity decrease for the two uncharged polymers. Poly(HEMA-co-MMA), the rigid polymer, exhibits greater ion selectivity while sorption behavior is not affected by polymer backbone rigidity.

To further explore the effect of backbone dynamics, the penetrant size range should be expanded in the salt selectivity experiments. Future efforts should be made on 
determining water diffusion coefficients by other methods such as pulsed gradient NMR study to verify the validity of gravimetric sorption results and boundary layer hypothesis.

\section{Reference}

[1] M. A. Shannon, P.W. Bohn, M. Elimelech, J.G. Georgiadis, B.J. Mariñas, A.M. Mayes, Science and technology for water purification in the coming decades, Nature. 452 (2008) 301-310. doi:10.1038/nature06599.

[2] J.T. Carlton, I.M. Parker, D. Simberloff, W.M. Lonsdale, K. Goodell, M. Wonham, et al., The United Nations World water Development report 2014, 2014.

[3] G.M. Geise, D.R. Paul, B.D. Freeman, Fundamental water and salt transport properties of polymeric materials, Prog. Polym. Sci. 39 (2014) 1-42. doi:10.1016/j.progpolymsci.2013.07.001.

[4] R. Semiat, Energy issues in desalination processes, Environ. Sci. Technol. 42 (2008) 8193-8201. doi:10.1021/es801330u.

[5] K.T. Sanders, M.E. Webber, Evaluating the energy consumed for water use in the United States, 034034 (n.d.). doi:10.1088/1748-9326/7/3/034034.

[6] B.D. Lutz, A.N. Lewis, M.W. Doyle, Generation , transport , and disposal of wastewater associated with Marcellus Shale gas development, 49 (2013) 647-656. doi:10.1002/wrcr.20096.

[7] S. Lattemann, M.D. Kennedy, J.C. Schippers, G. Amy, Global Desalination Situation, Elsevier, 2010. doi:10.1016/S1871-2711(09)00202-5.

[8] M. Elimelech, W. A Phillip, The future of seawater desalination: energy, technology, and the environment., Science. 333 (2011) 712-717. doi:10.1126/science.1200488.

[9] S. Report, Purification with a pinch of salt, 452 (2011) 260-261.

[10] U.S.E.I. Administration, March 2016 Monthly Energy Review, 2016.

[11] IEA-ETSAP and IRENA ${ }^{\odot}$ Technology Brief: Water Desalination Using Renewable Energy, (2012).

[12] K.S. Spiegler, Y.M. El-Sayed, The energetics of desalination processes, Desalination. 134 (2001) 109-128. doi:10.1016/S0011-9164(01)00121-7.

[13] G.M. Geise, H.-S. Lee, D.J. Miller, B.D. Freeman, J.E. McGrath, D.R. Paul, Water purification by membranes: The role of polymer science, J. Polym. Sci. Part B Polym. 
Phys. 48 (2010) 1685-1718. doi:10.1002/polb.22037.

[14] G.M. Geise, H.B. Park, A.C. Sagle, B.D. Freeman, J.E. McGrath, Water permeability and water/salt selectivity tradeoff in polymers for desalination, J. Memb. Sci. 369 (2011) 130138. doi:10.1016/j.memsci.2010.11.054.

[15] E.M. Vrijenhoek, S. Hong, M. Elimelech, Influence of membrane surface properties on initial rate of colloidal fouling of reverse osmosis and nanofiltration membranes, J. Memb. Sci. 188 (2001) 115-128. doi:10.1016/S0376-7388(01)00376-3.

[16] D. Li, H. Wang, Recent developments in reverse osmosis desalination membranes, J. Mater. Chem. 20 (2010) 4551. doi:10.1039/b924553g.

[17] N. Hilal, O.O. Ogunbiyi, N.J. Miles, R. Nigmatullin, Methods Employed for Control of Fouling in MF and UF Membranes: A Comprehensive Review, Sep. Sci. Technol. 40 (2005) 1957-2005. doi:10.1081/SS-200068409.

[18] T. Cath, A. Childress, M. Elimelech, Forward osmosis: Principles, applications, and recent developments, J. Memb. Sci. 281 (2006) 70-87. doi:10.1016/j.memsci.2006.05.048.

[19] M.M. Motsa, B.B. Mamba, A. D’Haese, E.M.V. Hoek, A.R.D. Verliefde, Organic fouling in forward osmosis membranes: The role of feed solution chemistry and membrane structural properties, J. Memb. Sci. 460 (2014) 99-109. doi:10.1016/j.memsci.2014.02.035.

[20] B.E. Logan, M. Elimelech, Membrane-based processes for sustainable power generation using water, Nature. 488 (2012) 313-319. doi:10.1038/nature11477.

[21] M.A. Hickner, Ion-containing polymers: new energy \& clean water, Mater. Today. 13 (2010) 34-41. doi:10.1016/S1369-7021(10)70082-1.

[22] A.Z. Weber, M.M. Mench, J.P. Meyers, P.N. Ross, J.T. Gostick, Q. Liu, Redox flow batteries: a review, J. Appl. Electrochem. 41 (2011) 1137-1164. doi:10.1007/s10800-011-0348-2.

[23] N.Y. Yip, A. Tiraferri, W.A. Phillip, J.D. Schiffman, L.A. Hoover, Y.C. Kim, et al., Thin-film composite pressure retarded osmosis membranes for sustainable power generation from salinity gradients, Environ. Sci. Technol. 45 (2011) 4360-4369. doi:10.1021/es104325z.

[24] G.M. Geise, M. A. Hickner, B.E. Logan, Ionic resistance and permselectivity tradeoffs in anion exchange membranes, ACS Appl. Mater. Interfaces. 5 (2013) 10294-10301. doi:10.1021/am403207w.

[25] J.G. Wijmans, R.W. Baker, The solution-diffusion model : a review, 107 (1995) 1-21.

[26] J. Lee, C.M. Doherty, A.J. Hill, S.E. Kentish, Water vapor sorption and free volume in the aromatic polyamide layer of reverse osmosis membranes, J. Memb. Sci. 425-426 (2013) 
217-226. doi:10.1016/j.memsci.2012.08.054.

[27] G.M. Geise, C.M. Doherty, A.J. Hill, B.D. Freeman, D.R. Paul, Free volume characterization of sulfonated styrenic pentablock copolymers using positron annihilation lifetime spectroscopy, J. Memb. Sci. 453 (2014) 425-434. doi:10.1016/j.memsci.2013.11.004.

[28] H. Chen, W.-S. Hung, C.-H. Lo, S.-H. Huang, M.-L. Cheng, G. Liu, et al., Free-Volume Depth Profile of Polymeric Membranes Studied by Positron Annihilation Spectroscopy: Layer Structure from Interfacial Polymerization, Macromolecules. 40 (2007) 7542-7557. doi:10.1021/ma071493w.

[29] L. Xi, M. Shah, B.L. Trout, Hopping of water in a glassy polymer studied via transition path sampling and likelihood maximization, J. Phys. Chem. B. 117 (2013) 3634-3647. doi:10.1021/jp3099973.

[30] F.M. Plathe, F. Muller-plathe, Diffusion of penetrants in amorphous polymers : A molecular dynamics study Diffusion of penetrants in amorphous polymers : A molecular dynamics study, 3192 (2000). doi:10.1063/1.459788.

[31] R.W. Baker, Membrane technology and applications. John Wiley \& Sons Ltd. (2004).

[32] C. Staudt-Bickel, W. J. Koros W., Improvement of CO2/CH4 separation characteristics of polyimides by chemical crosslinking, J. Memb. Sci. 155 (1999) 145-154. doi:10.1016/S0376-7388(98)00306-8.

[33] S. A Stern, V.M. Shah, B.J. Hardy, Structure-permeability relationships in silicone polymers, J. Polym. Sci. Part B Polym. Phys. 25 (1987) 1263-1298. doi:10.1002/polb.1987.090250607.

[34] B.D. Freeman, N. Carolina, Basis of Permeability/Selectivity Tradeoff Relations in Polymeric Gas Separation Membranes, (1999) 375-380.

[35] S.H. Maruf, D.U. Ahn, J. Pellegrino, J.P. Killgore, A.R. Greenberg, Y. Ding, Correlation between barrier layer $\mathrm{Tg}$ and a thin-film composite polyamide membrane's performance: Effect of chlorine treatment, J. Memb. Sci. 405-406 (2012) 167-175. doi:10.1016/j.memsci.2012.03.005.

[36] M. Paul, H.B. Park, B.D. Freeman, A. Roy, J.E. McGrath, J.S. Riffle, Synthesis and crosslinking of partially disulfonated poly(arylene ether sulfone) random copolymers as candidates for chlorine resistant reverse osmosis membranes, Polymer. 49 (2008) 22432252. doi:10.1016/j.polymer.2008.02.039.

[37] S.-Y. Kwak, Relationship of relaxation property to reverse osmosis permeability in aromatic polyamide thin-film-composite membranes, Polymer. 40 (1999) 6361-6368. doi:DOI: 10.1016/S0032-3861(98)00842-8.

[38] W. Xie, H. Ju, M. Geise, B.D. Freeman, J.I. Mardel, A.J. Hill, et al., Effect of Free 
Volume on Water and Salt Transport Properties in Directly Copolymerized Disulfonated Poly ( arylene ether sulfone ) Random Copolymers, (2011) 4428-4438.

[39] D. Paul, Reformulation of the solution-diffusion theory of reverse osmosis, J. Memb. Sci. 241 (2004) 371-386. doi:10.1016/j.memsci.2004.05.026.

[40] H. Ju, A.C. Sagle, B.D. Freeman, J.I. Mardel, A.J. Hill, Characterization of sodium chloride and water transport in crosslinked poly ( ethylene oxide ) hydrogels, J. Memb. Sci. 358 (2010) 131-141. doi:10.1016/j.memsci.2010.04.035.

[41] G.M. Geise, C.L. Willis, C.M. Doherty, A.J. Hill, T.J. Bastow, J. Ford, et al., Characterization of aluminum-neutralized sulfonated styrenic pentablock copolymer films, Ind. Eng. Chem. Res. 52 (2013) 1056-1068. doi:10.1021/ie202546z.

[42] W. Xie, J. Cook, H.B. Park, B.D. Freeman, C.H. Lee, J.E. McGrath, Fundamental salt and water transport properties in directly copolymerized disulfonated poly(arylene ether sulfone) random copolymers, Polymer (Guildf). 52 (2011) 2032-2043. doi:10.1016/j.polymer.2011.02.006.

[43] H. Yasuda, C. E. Lamaze,and L. D. Ikenberr, Permeability of Solutes through Hydrated Polymer Membranes, 118 (1968) 19-35.

[44] G.M. Geise, L.P. Falcon, B.D. Freeman, D.R. Paul, Sodium chloride sorption in sulfonated polymers for membrane applications, J. Memb. Sci. 423-424 (2012) 195-208. doi:10.1016/j.memsci.2012.08.014.

[45] J. Crank, THE MATHEMATICS OF DIFFUSION, (1975).

[46] K.S. Pitzer, A thermodynamic model for aqueous solutions of liquid-like density,Reviews in Mineralogy and Geochemistry., (1987) 97-142.

[47] M.H. Cohen, D. Turnbull, Molecular Transport in Liquids and Glasses, 1164 (2011). doi:10.1063/1.1730566.

[48] V. Freger, Swelling and morphology of the skin layer of polyamide composite membranes:An atomic force microscopy study, Environ. Sci. Technol. 38 (2004) 31683175. doi:10.1021/es034815u.

[49] M.A. Frommer, D. Lancet, Freezing and Nonfreezing Water in Cellulose Acetate Membranes, 16 (1972) 1295-1303.

[50] D.W.Van. Krevelen, Properties of Polymers, Elsevier, 2009.

[51] I.M. Hodge, I.M. Hodge, Physical Aging in Polymer Glasses Published by : American Association for the Advancement of Science Physical Aging in Polymer Glasses, 267 (2016) 1945-1947.

[52] W. Brostow, R. Chiu, I.M. Kalogeras, A. Vassilikou-Dova, Prediction of glass transition temperatures: Binary blends and copolymers, Mater. Lett. 62 (2008) 3152-3155. 
doi:10.1016/j.matlet.2008.02.008.

[53] H. Ju, A.C. Sagle, B.D. Freeman, J.I. Mardel, A.J. Hill, Characterization of sodium chloride and water transport in crosslinked poly(ethylene oxide) hydrogels, J. Memb. Sci. 358 (2010) 131-141. doi:10.1016/j.memsci.2010.04.035.

[54] D. Hofmann, L. Fritz, J. Ulbrich, C. Schepers, M. Bhning, Detailed-atomistic molecular modeling of small molecule diffusion and solution processes in polymeric membrane materials, Macromol. Theory Simulations. 9 (2000) 293-327. doi:10.1002/1521-3919(20000701)9:6<293::AID-MATS293>3.0.CO;2-1.

[55] A.L. Iordanskii, A.L. Shterenzon, Y. V Moiseev, G.E. Zaikov, Diffusion of Electrolytes in Polymers, Russ. Chem. Rev. 48 (1979) 781-797. doi:10.1070/RC1979v048n08ABEH002411.

[56] E.R. Nightingale, Phenomenological Theory of Ion Solvation. Effective Radii of Hydrated Ions, J. Phys. Chem. 63 (1959) 1381-1387. doi:10.1021/j150579a011.

[57] D.R. Lide, CRC Handbook of Chemistry and Physics, (2003) 3485. doi:978-1466571143.

[58] G.M. Geise, B.D. Freeman, D.R. Paul, Sodium chloride diffusion in sulfonated polymers for membrane applications, J. Memb. Sci. 427 (2013) 186-196.

doi:10.1016/j.memsci.2012.09.029. 